\title{
EFFECT OF CHEMICAL, BIO FERTILIZATION AND COMPOST TEA SPRAYING ON GROWTH AND PRODUCTIVITY OF ZANTEDESCHIA BULBS
}

\author{
Azza A. Ghazi ${ }^{*}$ and Eman A. Attia ${ }^{* *}$ \\ * Microbiology Dept., Soils, Water and Environ. Research Inst., ARC, Egypt. \\ ** Ornamental Plants and Landscape Gardening Res. Dept., Hort. Res. Inst., ARC, Egypt.
}

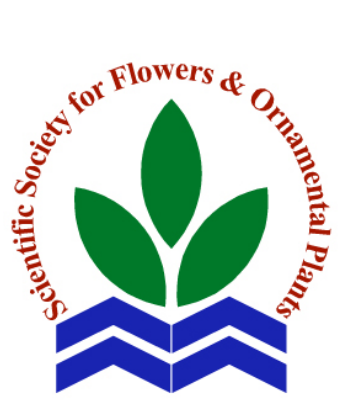

Scientific J. Flowers \& Ornamental Plants, 3(3):147-166 (2016).

Received: $1 / 9 / 2016$

Revised by: Prof. Dr. E.S. Nofal, Kafr El-Sheikh Univ.

Prof. Dr. Nadia A. Ali, Soil, Water and Environ. Res. Inst.,ARC.
ABSTRACT: A pot experiment was carried out during two successive seasons of 2013/2014 and 2014/2015 in a split design to determine if compost tea spraying and Enterobacter cloacae KX034162 inoculation under phosphorus fertilization levels influence plant development, rhizome weight and chemical constituents of Zantedeschia aethiopica plants. The study showed that generally E. cloacae KX034162 inoculation had a positive effect on growth, flowering and chemical constituents under the different phosphorus (p) fertilization levels. E. cloacae KX034162 inoculation under 50\% Prate of recommended dose combined with compost tea spraying resulted in a significant increase in plant height, number of leaves per clump, leaf area, shoot and rhizome fresh weight, rhizome dry weight, stalk length and diameter, inflorescence height and diameter, flowering spike fresh weight, N, P and $\mathrm{K}$ concentration in shoot, flowering period and flower date and increased activity of dehydrogenase in soil. While, total inflorescence clump ${ }^{-1}$ and vase life (days) were increased by inoculation with E. cloacae KX034162 under 75\% P-rate of the recommended dose combined with compost tea spraying.

Key words: Zantedeschia, biofertilization, compost tea, chemical fertilization

\section{INTRODUCTION}

Calla lily (Zantedeschia aethiopica family: Araceae) is a perennial herbaceous geophyte, gaining commercial importance as a cut flower plant. The principle aim of calla cultivation is to produce, in the shortest time, as many rhizomes as possible that will provide multiple flowered, quality plants, capable of flowering during given market periods or to maximize flower production on a specific time schedule, and optimizing rhizome quality for a specific number of production cycles.

Production of flowering plants can be greatly improved through regular care. As any other plants, fertilization plays a critical role in calla production through enhancement of yield and quality of the product. So, there is an increased demand to engineer new fertilizer formulae including bio fertilizers. Compost tea contains a set of aerobic organisms that perform a variety of beneficial functions in addition; it contains soluble nutrients that feed the organisms already within the tea and feed the plant, making it healthier (Pant et al., 2009 and Welke, 2005).

Plant growth promoting rhizobacteria (PGPR) like bacteria belonging to genera including Bacillus, Gluconacetobacter, Azoarcus, Azotobacter, Acetobacter, Azospirillum, Burkholderia, Enterobacter, Diazotrophicus, Pseudomonas and cyanobacteria (Anabaena, nostoc) can enhance plant yield either directly through 
their ability for nutrient supply (nitrogen, phosphorus, potassium and micro elements), regulating plant hormone system, or indirectly by decreasing the harm effects of various pathogens on plant growth and development in the forms of bio-control agents, root colonizers, and environmental protectors (Kloepper and Schroth, 1981; Vessey, 2003; Bhattacharyya and Jha, 2012)

Phosphorus is considered the most important key element in the nutrition of plants, next to nitrogen (N). It plays a vital role in almost all metabolic pathways in plant including photosynthesis, energy storing transfer, signal transduction, biosynthesis of macromolecules and respiration (Khan et al., 2010). Plant growth promoting rhizobacteria employ different mechanisms to make use of unavailable forms of phosphorus and making it available for plants to absorb as include: (1) release of mineral dissolving compounds e.g. organic acid anions, protons, hydroxyl ions, $\mathrm{CO}_{2},(2)$ production of extracellular enzymes (e.g. phosphatases) and (3) release of phosphate during organic substrate decomposition (biological phosphate mineralization) Sharma et al., 2013.

In Zantedeschia, inflorescence differentiation occurs in tissue culture plantlets after treatment with gibberellin (GA3) application (Naor et al., 2004). Moreover, application of GA enhances flowering in other Araceae species (Henny, 1999) and is used commercially to increase the flower productivity of colored cultivars of calla lily (Funnell, 1993). PGPR can produce phytohormones as gibberellins and indole acetic acide (IAA) providing a phytohormonal pool for regulation and enhancement of plant life cycle (Verma and Shahi, 2015; Gupta et al., 2015). Enterobacter $s p$ are known to solubilize insoluble phosphate and make it available to plants. They are also capable of producing phytohormones like IAA (Saharan and Nehra, 2011).

Compost tea is the commercially popularized term for an infusion where compost is soaked in water for a period of time with the aim of transferring soluble organic matter, beneficial micro-organisms and macro- and micro-nutrients into solution (Ingram and Millner, 2007). The use of compost tea in organic agriculture is gaining popularity for improving soil biology and fertility (Diver, 2007).

Hargreaves et al. (2009) found that compost tea maintained plant nutrient concentrations comparable to the addition of ruminant compost, municipal solid waste MSW compost, and inorganic fertilizer so, it can serve as an effective source of nutrients.

This study is a trial to evaluate the efficiency of inoculation with Enterobacter coloacea combined with spraying with compost tea as a way to decrease phosphate fertilization and enhance plant productivity.

\section{MATERIALS AND METHODS}

This investigation was conducted at the Experimental Greenhouse of Horticulture Research Station at Sakha, Kafr El-Sheikh Governorate. The experimental design was a split plot with four replications during 20132014 and 2014-2015, the main factor is spraying with compost tea (1) control (2) spraying with compost tea and sub main is Enterobacter cloacae inoculation under different phosphorus fertilizer levels $(15.5 \%$ $\mathrm{P}_{2} \mathrm{O}_{5}$ ) (a) control (b) $100 \%$ P-rate of recommended dose equal $7.0 \mathrm{~g} \mathrm{plant}^{-1}$ (c) $75 \% \mathrm{P}=5.25 \mathrm{~g} \mathrm{plant}^{-1} \quad$ (d) $50 \% \mathrm{P}=3.5 \mathrm{~g}$ plant $^{-1}$ (e) E. cloacae (f) E. cloacae KX034162 +100\% P (g) E. cloacae $+75 \% \mathrm{P}$ (h) E. cloacae $+50 \% \mathrm{P}$.

These treatments were replicated four times and each replicate contained one plant, the experiment contained 64 plants for each season, in addition $4.0 \mathrm{~g} \mathrm{plant}^{-1}$ potassium sulphate $\left(\begin{array}{lll}48 \% & \left.\mathrm{~K}_{2} \mathrm{O}\right)\end{array}\right)$ and $4.0 \mathrm{~g}$ plant $^{-1}$ ammonium sluphate $(20.5 \mathrm{~N})$ in all treatments. Recommended doses were applied as mentioned by Attia, (2004).

\section{Biofertilizer:}

In this study, a biofertilizer of E. cloacae was obtained from Bacteriology Lab., Sakha 
Agricultural Research Station. E. cloacae was produced with the density of about $1 \times$ 109. $\mathrm{Ml}^{-1}$ and mixed with a carrier (peat:vermiculite 1:1 w/w) and used with the rate of $3 \mathrm{~g} \mathrm{pot}^{-1}$ at sowing, each pot contain $10 \mathrm{~kg}$ sandy clay loam soil.

The chemical properties of the studied soil were determined before cultivation process according to Black et al. (1965) and Jackson (1967). The particle size distribution was determined according to the international method (Klute, 1986).

\section{Data recorded:}

Growth parameters: number of vegetative and flowering characters was assessed, including plant height, number of leaves per main shoot and clump, total shoot number per clump, leaf blade length $(\mathrm{cm})$, leaf area $\left(\mathrm{cm}^{2}\right)$, dry weight of shoot and rhizome (g), fresh weight of shoot and rhizome ( $\left.\mathrm{g} \mathrm{plant}^{-1}\right)$, stalk length and diameter (cm), flowering spike fresh and dry weight (g), vase life (days), total inflorescence per clump, inflorescence diameter and height (cm), flowering date and flowering period, dry matter percentage using the methods described by A.O.A.C (1984).

\section{Chemical components:}

Chemical constituents of shoot were assayed for total nitrogen (Black et al., 1965) Phosphorus percentage (Snell and Snell, 1967) and potassium was determined using the flame photometer according to the method described by Brown and Lilliland (1946).

Table (1). Some physical and chemical properties of the experimental site.

\begin{tabular}{|c|c|c|c|c|c|c|c|c|c|c|c|}
\hline \multirow[b]{2}{*}{ OM\% } & \multicolumn{4}{|c|}{ Soluble anions (meq/l) } & \multicolumn{4}{|c|}{ Soluble cations (meq/l) } & \multicolumn{3}{|c|}{ Available macro-elements } \\
\hline & $\mathrm{SO}_{4}^{-2}$ & $\mathrm{Cl}^{-}$ & $\mathrm{HCO}_{3}^{-}$ & $\mathrm{CO}_{3}^{--}$ & $\mathbf{N a}^{+}$ & $\mathbf{K}^{+}$ & $\mathbf{M g}^{2+}$ & $\mathrm{Ca}^{2+}$ & $\begin{array}{c}P \\
\left(\mathrm{mg} \mathrm{kg}^{-1}\right)\end{array}$ & $\begin{array}{c}\mathrm{N} \\
\left(\mathrm{mg} \mathrm{kg}^{-1}\right)\end{array}$ & $\begin{array}{c}\mathrm{K} \\
\left(\mathrm{mg} \mathrm{kg}^{-1}\right)\end{array}$ \\
\hline 1.2 & 19.84 & 14.98 & 5.79 & 0.0 & 23.13 & 0.4 & 5.27 & 11.74 & 18.74 & 24.3 & 93.8 \\
\hline \multicolumn{2}{|c|}{ Texture grade } & Clay \% & Par & $\begin{array}{l}\text { icle size } \\
\%\end{array}$ & $\begin{array}{l}\text { distribu } \\
\text { C. } \\
\text { sand \% }\end{array}$ & ition & $\begin{array}{l}F . \\
\text { sand } \%\end{array}$ & & \multicolumn{2}{|c|}{$\begin{array}{c}\text { EC } \\
\text { dS.m-1 } \\
\text { In soil paste } \\
\text { extract } \\
\end{array}$} & $\begin{array}{c}\text { P H } \\
1: 2.5 \\
\text { suspension }\end{array}$ \\
\hline \multicolumn{2}{|c|}{ Sandy clay loam } & 36.2 & 22 & & 28.4 & & 13.0 & & 4.16 & & 8.4 \\
\hline
\end{tabular}


Table (2). Chemical characters of the compost.

\begin{tabular}{cc}
\hline Property & Compost \\
\hline Moisture & 36.2 \\
$\mathrm{pH}$ & 6.12 \\
$\mathrm{Ec}\left(\mathrm{ds} \mathrm{m}^{-1}\right)$ & 10.62 \\
$\mathrm{O} . \mathrm{M} \%$ & 32.57 \\
Total N\% & 1.21 \\
Total $\%$ & 0.47 \\
Total K\% & 0.80 \\
$\mathrm{Ca} \%$ & 1.5 \\
$\mathrm{Mg}^{++} \%$ & 0.14 \\
$\mathrm{Fe}(\mathrm{ppm})$ & 15068 \\
$\mathrm{Mn}(\mathrm{ppm})$ & 598 \\
$\mathrm{Zn}(\mathrm{ppm})$ & 65 \\
$\mathrm{Cu}(\mathrm{ppm})$ & 57 \\
\hline
\end{tabular}

compared using L.S.D. according to Steel and Torrie (1980), test at 5\% level of significance $(p=0.05)$ was used for means comparison according to Snedecor and Cochran (1989).

\section{RESULTS AND DISCUSSION}

\section{Vegetative growth:}

Data resulted in Table (3) showed that plants inoculated with E. cloacae combined with $50 \%$ phosphorus fertilizer of recommended dose and using compost tea spray resulted in the tallest plants (57.0) during the first season followed by plants inoculated with $E$. cloacae, fertilized with $75 \%$ phosphorus fertilizer and sprayed with compost tea $(53.0 \mathrm{~cm})$ at the first seasons. As shown in Table (3) inoculation with $E$. cloacae under different phosphorus levels increased number of leaves per main shoot. The maximum number of leaves main shoot $^{-1}$ was obtained with inoculation with $E$. cloacae and applying $75 \%$ phosphorus fertilizer of the recommended dose as shown in Figure (1) giving 8.83 and 8.17 in both seasons respectively. Interaction effect between bio, chemical fertilizer and spraying with compost tea had a non-significant influence on number of leaves per main shoot but had highly significant effect on number of leaves per clump, the maximum number of leaves clump ${ }^{-1}$ was obtained with treating the plants with $50 \%$ phosphorus fertilizer of the recommended dose, inoculating with $E$. cloacae and spraying with compost tea as raised number of leaves clump $^{-1}$ (29 and 28.7) in the two seasons respectively. This may be due to that phosphate dissolving bacteria (E. cloacae) enhance the plant height, number of leaves in clump and in main shoot by increasing the available $\mathrm{P}$ in soil which in turn promotes cell division and the develops the meristematic tissue (Abo El-Nour et al., 1996 and Youssef et al., 2001).

\section{Shoots number per clump, leaf area and leaf blade length:}

E. cloacae inoculation increased shoot number clump $^{-1}$ under the different phosphorus levels as shown in Figure (2). Plants inoculated with E. cloacae and fertilized with $75 \%$ phosphorus fertilizer of the recommended dose raised values to 5.67 and 5.5 more than control during the two seasons respectively.

Data resulted in Table (4) illustrated that inoculation with $E$. cloacae under all fertilization treatments raised leaf blade length $(\mathrm{cm})$ as compared with control. On the other hand spraying with compost tea increased leaf blade length $(\mathrm{cm})$ during the two seasons over control. Highly significant effect for the interaction between phosphorus fertilizer combined with $E$. cloacae inoculation and spraying with compost tea on leaf blade length $(\mathrm{cm})$ were obtained as 36.7 and 34.3 obtained with $50 \%$ phosphorus fertilizer of the recommended dose and inoculation with $E$. cloacae under spraying plants with compost tea in both seasons respectively. In the same trend leaf area $(\mathrm{cm})$ were increased under this conditions recorded 282.1 and 296 compared to control during the two seasons.

Results presented in Tables (5 and 6) showed that fresh and dry weight of shoot and rhizome were increased by inoculation with E. cloacae combined with phosphorus fertilizer compared to control. The interaction effect between chemical and biofertilizer of phosphorus combined with compost tea spraying caused high significant 
Table (3). Effect of chemical, biofertilization and spraying with compost tea on plant height and number of leave per main shoot and clump of Zantedeschia aethiopica L. in two seasons.

\begin{tabular}{|c|c|c|c|c|c|c|c|}
\hline \multicolumn{2}{|c|}{ Treatments } & \multicolumn{2}{|c|}{ Plant height (cm) } & \multicolumn{2}{|c|}{ No. of leaves / main shoot } & \multicolumn{2}{|c|}{ No. of leaves/ clump } \\
\hline Main & Sub plot & Season 1 & Season 2 & Season 1 & Season 2 & Season 1 & Season 2 \\
\hline \multirow[t]{8}{*}{ Control } & Control & 37.0 & 36.7 & 5.3 & 5.33 & 8.7 & 9.0 \\
\hline & $100 \% P$ & 43.3 & 43.7 & 7.0 & 7.67 & 17.3 & 15.3 \\
\hline & $75 \% P$ & 43.7 & 41.7 & 6.3 & 6.33 & 11.7 & 14.3 \\
\hline & $50 \% \mathrm{p}$ & 38.3 & 38.0 & 6.0 & 5.67 & 10.7 & 11.7 \\
\hline & E. cloacae & 39.3 & 39.0 & 7.0 & 7.00 & 11.0 & 10.3 \\
\hline & $E .+100 \% \mathrm{P}$ & 48.0 & 48.3 & 8.3 & 8.67 & 20.7 & 22.0 \\
\hline & $E .+75 \% \mathrm{P}$ & 49.7 & 49.7 & 8.3 & 8.00 & 21.7 & 22.7 \\
\hline & $E .+50 \% \mathrm{P}$ & 43.0 & 42.0 & 6.3 & 6.33 & 17.3 & 15.7 \\
\hline \multirow[t]{8}{*}{ Compost tea } & Control & 39.7 & 41.0 & 6.0 & 6.33 & 13.3 & 13.0 \\
\hline & $100 \% P$ & 49.0 & 49.3 & 7.0 & 7.33 & 21.3 & 22.7 \\
\hline & $75 \% P$ & 45.0 & 45.7 & 6.7 & 6.67 & 21.0 & 19.7 \\
\hline & $50 \% p$ & 42.7 & 43.7 & 6.3 & 7.00 & 20.0 & 19.3 \\
\hline & E. cloacae & 48.3 & 50.0 & 6.7 & 7.00 & 20.3 & 21.3 \\
\hline & $E .+100 \% \mathrm{P}$ & 52.0 & 52.7 & 8.3 & 8.33 & 28.7 & 28.3 \\
\hline & $E .+75 \% \mathrm{P}$ & 53.0 & 52.3 & 7.3 & 7.33 & 27.7 & 28.7 \\
\hline & $E .+50 \% \mathrm{P}$ & 57.0 & 55.3 & 8.3 & 7.67 & 29.00 & 28.7 \\
\hline F. Test & & $*$ & N.S & N.S & N.S & $*$ & $*$ \\
\hline L.S.D 0.05 & & 5.49 & -- & -- & -- & 3.4 & 3.68 \\
\hline \multicolumn{8}{|c|}{ Main plot } \\
\hline \multicolumn{2}{|c|}{ Control } & 42.79 & 42.38 & 6.83 & 6.88 & 14.88 & 15.13 \\
\hline \multicolumn{2}{|c|}{ Compost tea } & 48.33 & 48.75 & 7.33 & 7.21 & 22.67 & 22.71 \\
\hline \multirow{2}{*}{\multicolumn{2}{|c|}{$\begin{array}{l}\text { F. Test } \\
\text { LSD } 0.05\end{array}$}} & $* *$ & $* *$ & N.S & N.S & $* *$ & $* *$ \\
\hline & & 1.94 & 2.16 & -- & -- & 1.2 & 1.3 \\
\hline \multicolumn{8}{|c|}{ Sub plot } \\
\hline \multicolumn{2}{|c|}{ Control } & 38.33 & 38.83 & 5.67 & 5.83 & 11.00 & 11.00 \\
\hline \multicolumn{2}{|c|}{$100 \% P$} & 46.17 & 46.50 & 7.00 & 7.50 & 19.33 & 19.00 \\
\hline \multicolumn{2}{|c|}{$75 \% \mathrm{P}$} & 44.33 & 43.67 & 6.50 & 6.50 & 16.33 & 17.00 \\
\hline \multicolumn{2}{|c|}{$50 \% p$} & 40.50 & 40.83 & 6.17 & 6.33 & 15.33 & 15.50 \\
\hline \multicolumn{2}{|c|}{ E. cloacae } & 43.83 & 44.50 & 6.83 & 7.00 & 15.67 & 15.83 \\
\hline \multicolumn{2}{|c|}{$E .+100 \% \mathrm{P}$} & 50.00 & 50.50 & 7.33 & 7.67 & 24.63 & 25.33 \\
\hline \multicolumn{2}{|c|}{$E .+75 \% \mathrm{P}$} & 51.33 & 51.00 & 8.83 & 8.17 & 24.87 & 25.50 \\
\hline \multicolumn{2}{|c|}{$E .+50 \% \mathrm{P}$} & 50.00 & 48.67 & 8.33 & 7.33 & 23.00 & 22.17 \\
\hline \multicolumn{2}{|l|}{ F. Test } & $* *$ & $* *$ & $* *$ & $* *$ & $* *$ & $* *$ \\
\hline \multicolumn{2}{|l|}{ LSD 0.05} & 3.89 & 4.32 & 1.00 & 1.14 & 2.41 & 2.6 \\
\hline
\end{tabular}

N.S $=$ Non significant, $*=$ significant and $* *=$ highly significant 


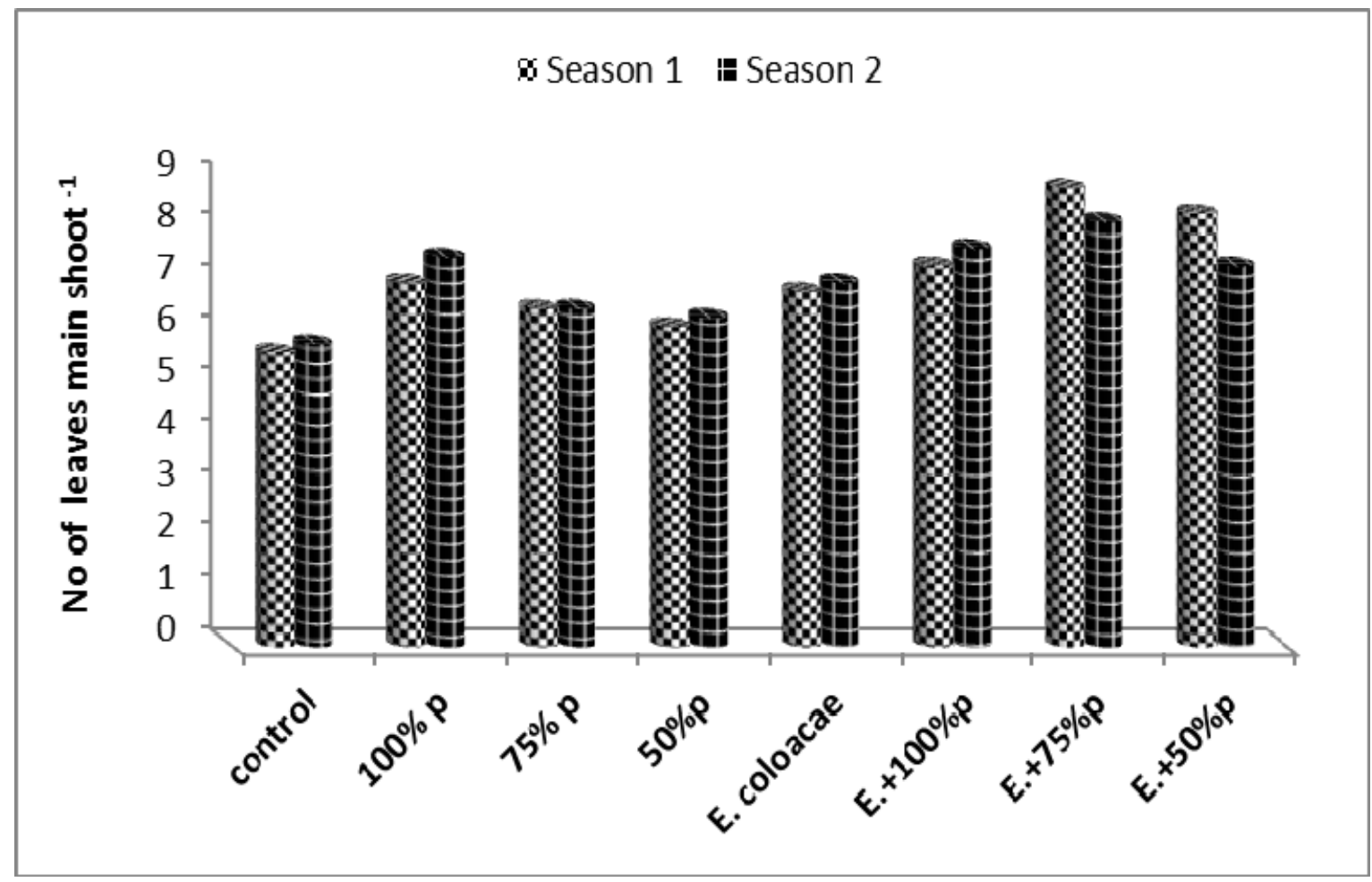

Figure (1). Number of leaves of Zantedeschia aethiopica L. in two seasons as affected by $E$. cloacae under phosphorus fertilization levels.

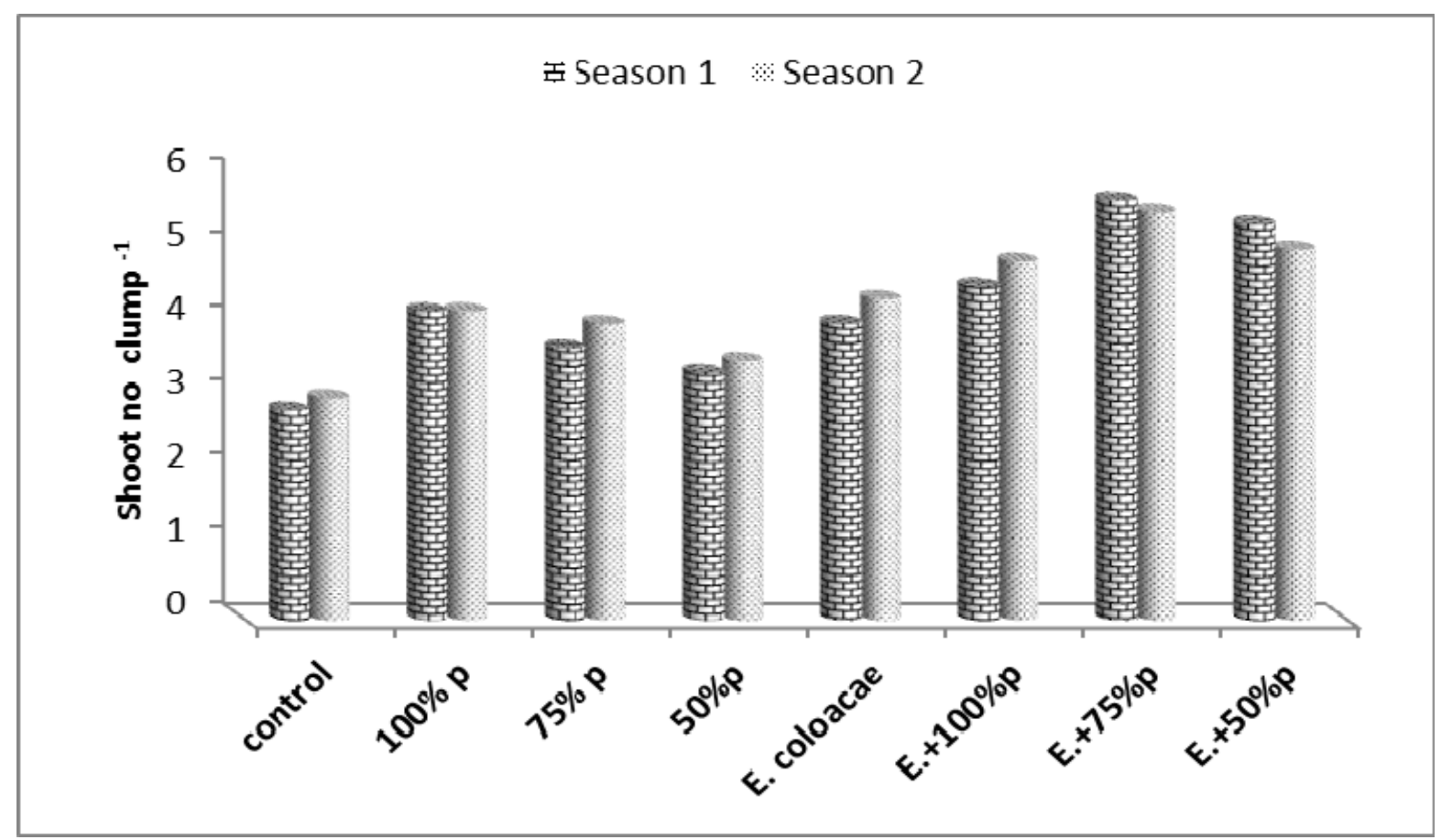

Figure (2). Number of shoot per clump of Zantedeschia aethiopica L. in two seasons as affected by $E$. cloacae under phosphorus fertilization levels. 
Table (4). Effect of chemical, biofertilization and spraying with compost tea on shoot number per clump, leaf blade length and leaf area of Zantedeschia aethiopica $\mathrm{L}$. in two seasons.

\begin{tabular}{|c|c|c|c|c|c|c|c|}
\hline \multicolumn{2}{|c|}{ Treatments } & \multicolumn{2}{|c|}{$\begin{array}{c}\text { Total shoots number/ } \\
\text { Clump }\end{array}$} & \multicolumn{2}{|c|}{ Leaf blade length $(\mathrm{cm})$} & \multicolumn{2}{|c|}{ Leaf area $\left(\mathrm{cm}^{2}\right)$} \\
\hline Main & Sub plot & Season 1 & Season 2 & Season 1 & Season 2 & Season 1 & Season 2 \\
\hline \multirow[t]{8}{*}{ Control } & Control & 2.33 & 2.00 & 19.0 & 19.7 & 111.3 & 111.7 \\
\hline & $100 \% P$ & 3.33 & 3.00 & 30.0 & 31.0 & 192.3 & 200.3 \\
\hline & $75 \% \mathrm{P}$ & 3.00 & 3.00 & 27.0 & 27.3 & 167.0 & 169.4 \\
\hline & $50 \%$ p & 3.00 & 2.67 & 22.3 & 22.0 & 136.2 & 136.9 \\
\hline & E. cloacae & 3.00 & 3.67 & 21.3 & 21.7 & 142.6 & 145.9 \\
\hline & $E .+100 \% P$ & 3.67 & 4.33 & 30.0 & 30.0 & 189.3 & 193.6 \\
\hline & $E .+75 \% \mathrm{P}$ & 5.33 & 5.33 & 31.0 & 29.7 & 192.1 & 196.8 \\
\hline & $E .+50 \% \mathrm{P}$ & 5.00 & 4.33 & 27.7 & 25.7 & 156.6 & 169.1 \\
\hline \multirow[t]{8}{*}{ Compost tea } & Control & 3.33 & 4.00 & 22.7 & 22.3 & 132.3 & 137.3 \\
\hline & $100 \% \mathrm{P}$ & 5.00 & 5.33 & 29.0 & 28.3 & 252.1 & 266.1 \\
\hline & $75 \% \mathrm{P}$ & 4.33 & 5.00 & 26.0 & 26.0 & 223.7 & 224.5 \\
\hline & $50 \% \mathrm{p}$ & 3.67 & 4.33 & 21.3 & 23.3 & 192.9 & 191.2 \\
\hline & E. cloacae & 5.00 & 5.00 & 32.3 & 31.0 & 191.4 & 182.4 \\
\hline & $E .+100 \% \mathrm{P}$ & 5.33 & 5.33 & 32.7 & 32.7 & 264.4 & 285.5 \\
\hline & $E .+75 \% \mathrm{P}$ & 6.00 & 5.67 & 36.0 & 33.0 & 277.7 & 279.5 \\
\hline & $E .+50 \% \mathrm{P}$ & 5.67 & 5.67 & 36.7 & 34.3 & 282.1 & 296.0 \\
\hline F. Test & & N.S & N.S & $* *$ & $* *$ & $* *$ & $* *$ \\
\hline L.S.D 0.05 & & -- & -- & 3.24 & 4.08 & 31.98 & 18.54 \\
\hline \multicolumn{8}{|c|}{ Main plot } \\
\hline \multicolumn{2}{|c|}{ Control } & 3.58 & 3.54 & 26.04 & 25.88 & 160.92 & 165.47 \\
\hline \multicolumn{2}{|c|}{ Compost tea } & 4.79 & 5.04 & 29.58 & 28.88 & 227.08 & 232.83 \\
\hline & $* *$ & $* *$ & $* *$ & $* *$ & $* *$ & $* *$ \\
\hline \multicolumn{2}{|l|}{ LSD 0.05} & 0.33 & 0.4 & 1.14 & 1.44 & 11.31 & 6.56 \\
\hline \multicolumn{8}{|c|}{ Sub plot } \\
\hline \multicolumn{2}{|c|}{ Control } & 2.83 & 3.00 & 20.83 & 21.00 & 121.78 & 124.53 \\
\hline \multicolumn{2}{|c|}{$100 \% P$} & 4.17 & 4.17 & 29.50 & 29.67 & 222.16 & 233.22 \\
\hline \multicolumn{2}{|c|}{$75 \% \mathrm{P}$} & 3.67 & 4.00 & 26.50 & 26.67 & 195.37 & 196.94 \\
\hline \multicolumn{2}{|c|}{$50 \%$ p } & 3.33 & 3.50 & 21.83 & 22.67 & 164.61 & 164.09 \\
\hline \multicolumn{2}{|c|}{ E. cloacae } & 4.00 & 4.33 & 26.83 & 26.33 & 167.01 & 164.20 \\
\hline \multicolumn{2}{|c|}{$E .+100 \% \mathrm{P}$} & 4.50 & 4.83 & 33.00 & 31.50 & 226.83 & 238.83 \\
\hline \multicolumn{2}{|c|}{$E .+75 \% \mathrm{P}$} & 5.67 & 5.50 & 31.83 & 31.17 & 234.91 & 244.13 \\
\hline \multicolumn{2}{|c|}{$E .+50 \% \mathrm{P}$} & 5.33 & 5.00 & 32.17 & 30.00 & 219.34 & 227.29 \\
\hline \multicolumn{2}{|l|}{ F. Test } & $* *$ & $* *$ & $* *$ & $* *$ & $* *$ & $* *$ \\
\hline \multicolumn{2}{|l|}{ LSD 0.05} & 0.66 & 0.8 & 2.29 & 2.89 & 22.61 & 13.11 \\
\hline
\end{tabular}

N.S= Non significant, $*$ significant and $* *=$ highly significant 
Table (5). Effect of chemical, biofertilization and spraying with compost tea on fresh weight of shoot and rhizome and dry weight of shoot $\left(g\right.$ plant $\left.^{-1}\right)$ of Zantedeschia aethiopica L. in two seasons.

\begin{tabular}{|c|c|c|c|c|c|c|c|}
\hline \multicolumn{2}{|c|}{ Treatments } & \multicolumn{2}{|c|}{$\begin{array}{l}\text { Shoot fresh weight } \\
\left(\text { g plant }^{-1}\right)\end{array}$} & \multicolumn{2}{|c|}{$\begin{array}{l}\text { Shoot dry weight } \\
\quad\left(\text { g plant }^{-1}\right)\end{array}$} & \multicolumn{2}{|c|}{$\begin{array}{l}\text { Rhizome fresh weight } \\
\qquad\left(\text { g plant }^{-1}\right)\end{array}$} \\
\hline Main & Sub plot & Season 1 & Season 2 & Season 1 & Season 2 & Season 1 & Season 2 \\
\hline \multirow[t]{8}{*}{ Control } & Control & 127.3 & 145.0 & 13.3 & 15.3 & 212.7 & 221.7 \\
\hline & $100 \% \mathrm{P}$ & 231.7 & 233.7 & 19.2 & 21.5 & 245.2 & 241.7 \\
\hline & $75 \% \mathrm{P}$ & 170.2 & 204.9 & 17.4 & 19.2 & 221.9 & 220.3 \\
\hline & $50 \% p$ & 148.2 & 196.2 & 15.4 & 15.7 & 233.4 & 243.5 \\
\hline & E. cloacae & 206.8 & 196.5 & 17.5 & 19.9 & 239.2 & 250.8 \\
\hline & $E .+100 \% P$ & 236.6 & 240.6 & 24.6 & 25.0 & 326.6 & 320.6 \\
\hline & $E .+75 \% \mathrm{P}$ & 238.8 & 239.5 & 27.9 & 27.6 & 314.5 & 319.6 \\
\hline & $E .+50 \% \mathrm{P}$ & 196.6 & 181.1 & 20.8 & 21.5 & 269.0 & 273.8 \\
\hline \multirow[t]{8}{*}{ Compost tea } & Control & 179.9 & 182.3 & 15.9 & 17.2 & 204.9 & 206.6 \\
\hline & $100 \% \mathrm{P}$ & 255.6 & 257.6 & 25.9 & 24.9 & 280.3 & 281.7 \\
\hline & $75 \% P$ & 242.8 & 241.1 & 23.2 & 22.5 & 238.5 & 237.7 \\
\hline & $50 \% \mathrm{p}$ & 233.3 & 227.2 & 22.1 & 21.5 & 223.9 & 230.4 \\
\hline & E. cloacae & 205.7 & 213.7 & 20.2 & 21.6 & 307.9 & 307.8 \\
\hline & $E .+100 \% P$ & 267.4 & 268.1 & 28.4 & 32.1 & 339.9 & 339.5 \\
\hline & $E .+75 \% \mathrm{P}$ & 263.9 & 253.6 & 29.7 & 30.3 & 322.9 & 321.2 \\
\hline & $E .+50 \% \mathrm{P}$ & 276.2 & 271.6 & 31.0 & 30.8 & 359.9 & 346.3 \\
\hline F. Test & & $* *$ & $* *$ & N.S & N.S & $* *$ & $* *$ \\
\hline L.S.D 0.05 & & 20.87 & 20.14 & -- & -- & 22.38 & 25.04 \\
\hline \multicolumn{8}{|c|}{ Main plot } \\
\hline \multicolumn{2}{|c|}{ Control } & 194.51 & 208.44 & 19.49 & 20.72 & 265.96 & 264.82 \\
\hline \multicolumn{2}{|c|}{ Compost tea } & 240.59 & 239.39 & 24.57 & 25.08 & 279.09 & 280.60 \\
\hline \multirow{2}{*}{\multicolumn{2}{|c|}{$\begin{array}{l}\text { F. Test } \\
\text { LSD } 0.05\end{array}$}} & $* *$ & $* *$ & $* *$ & $* *$ & $* *$ & $* *$ \\
\hline & & 7.38 & 7.12 & 2.68 & 1.32 & 7.91 & 8.85 \\
\hline \multicolumn{8}{|c|}{ Sub plot } \\
\hline \multicolumn{2}{|c|}{ Control } & 153.63 & 163.62 & 14.62 & 16.23 & 208.76 & 214.15 \\
\hline \multicolumn{2}{|c|}{$100 \% \mathrm{P}$} & 243.64 & 245.66 & 22.56 & 23.23 & 262.75 & 261.72 \\
\hline \multicolumn{2}{|c|}{$75 \% P$} & 206.48 & 223.01 & 20.30 & 20.83 & 230.20 & 229.00 \\
\hline \multicolumn{2}{|c|}{$50 \% \mathrm{p}$} & 190.72 & 211.71 & 18.73 & 18.58 & 228.69 & 236.91 \\
\hline \multicolumn{2}{|c|}{ E. cloacae } & 206.23 & 205.08 & 18.84 & 20.70 & 273.53 & 279.29 \\
\hline \multicolumn{2}{|c|}{$E .+100 \% \mathrm{P}$} & 251.33 & 256.11 & 27.79 & 28.55 & 341.20 & 330.02 \\
\hline \multicolumn{2}{|c|}{$E .+75 \% \mathrm{P}$} & 256.40 & 261.51 & 28.81 & 28.97 & 343.38 & 333.74 \\
\hline \multicolumn{2}{|c|}{$E .+50 \% \mathrm{P}$} & 231.99 & 224.59 & 24.56 & 26.12 & 291.73 & 296.83 \\
\hline \multicolumn{2}{|c|}{ F. Test } & $* *$ & $* *$ & $* *$ & $* *$ & $* *$ & $* *$ \\
\hline \multicolumn{2}{|l|}{ LSD 0.05} & 14.76 & 14.24 & 1.34 & 2.64 & 15.83 & 17.70 \\
\hline
\end{tabular}

N.S $=$ Non significant, $*=$ significant and $* *=$ highly significant 
Table (6). Effect of chemical, biofertilization and spraying with compost tea on dry weight of rhizome $\left(\mathrm{g}\right.$ plant $\left.^{-1}\right)$ and stalk length and diameter $(\mathrm{cm})$ of Zantedeschia aethiopica L. in two seasons.

\begin{tabular}{|c|c|c|c|c|c|c|c|}
\hline \multicolumn{2}{|c|}{ Treatments } & \multicolumn{2}{|c|}{$\begin{array}{l}\text { Rhizome dry weight } \\
\quad\left(\text { g plant }^{-1}\right)\end{array}$} & \multicolumn{2}{|c|}{$\begin{array}{l}\text { Stalk length } \\
\quad(\mathrm{cm})\end{array}$} & \multicolumn{2}{|c|}{$\begin{array}{l}\text { Stalk diameter } \\
(\mathrm{cm})\end{array}$} \\
\hline Main & Sub plot & Season 1 & Season 2 & Season 1 & Season 2 & Season 1 & Season 2 \\
\hline \multirow[t]{8}{*}{ Control } & Control & 43.19 & 42.53 & 32.26 & 34.67 & 1.07 & 1.13 \\
\hline & $100 \% \mathrm{P}$ & 89.90 & 95.04 & 55.71 & 59.36 & 1.50 & 1.40 \\
\hline & $75 \% P$ & 78.07 & 82.06 & 50.38 & 51.63 & 1.33 & 1.40 \\
\hline & $50 \% \mathrm{p}$ & 66.67 & 71.63 & 38.36 & 39.73 & 1.20 & 1.07 \\
\hline & E. cloacae & 84.17 & 94.56 & 46.79 & 47.44 & 1.20 & 1.23 \\
\hline & $E .+100 \% \mathrm{P}$ & 122.98 & 113.45 & 60.33 & 60.35 & 1.83 & 1.77 \\
\hline & $E .+75 \% \mathrm{P}$ & 118.40 & 120.03 & 61.14 & 60.32 & 2.17 & 2.17 \\
\hline & $E .+50 \% \mathrm{P}$ & 118.57 & 124.80 & 44.59 & 45.44 & 1.37 & 1.30 \\
\hline \multirow[t]{8}{*}{ Compost tea } & Control & 66.91 & 65.78 & 37.73 & 36.90 & 1.07 & 1.07 \\
\hline & $100 \% \mathrm{P}$ & 88.05 & 89.14 & 55.97 & 56.33 & 1.50 & 1.50 \\
\hline & $75 \% \mathrm{P}$ & 75.98 & 77.97 & 51.00 & 53.23 & 1.15 & 1.13 \\
\hline & $50 \% p$ & 71.27 & 75.56 & 48.97 & 50.67 & 1.17 & 1.33 \\
\hline & E. cloacae & 79.38 & 78.43 & 59.17 & 59.87 & 1.33 & 1.30 \\
\hline & $E .+100 \% P$ & 120.55 & 123.96 & 59.57 & 59.10 & 2.13 & 2.23 \\
\hline & $E .+75 \% \mathrm{P}$ & 165.09 & 165.60 & 59.63 & 59.40 & 2.53 & 2.50 \\
\hline & $E .+50 \% \mathrm{P}$ & 171.16 & 169.85 & 62.73 & 62.23 & 2.57 & 2.57 \\
\hline F. Test & & $* *$ & $* *$ & $* *$ & $* *$ & $* *$ & $* *$ \\
\hline L.S.D 0.05 & & 10.3 & 10.57 & 5.66 & 4.86 & 0.21 & 0.25 \\
\hline \multicolumn{8}{|c|}{ Main plot } \\
\hline \multicolumn{2}{|c|}{ Control } & 92.94 & 93.04 & 48.82 & 49.99 & 1.46 & 1.43 \\
\hline \multicolumn{2}{|c|}{ Compost tea } & 102.10 & 105.76 & 54.22 & 54.72 & 1.68 & 1.70 \\
\hline \multirow{2}{*}{\multicolumn{2}{|c|}{$\begin{array}{l}\text { F. Test } \\
\text { LSD } 0.05\end{array}$}} & $* *$ & $* *$ & $* *$ & $* *$ & $* *$ & $* *$ \\
\hline & & 3.65 & 3.74 & 2.00 & 1.72 & 0.07 & 0.09 \\
\hline \multicolumn{8}{|c|}{ Sub plot } \\
\hline \multicolumn{2}{|c|}{ Control } & 55.05 & 54.16 & 35.00 & 35.79 & 1.07 & 1.10 \\
\hline \multicolumn{2}{|c|}{$100 \% \mathrm{P}$} & 88.98 & 92.09 & 55.84 & 57.85 & 1.50 & 1.45 \\
\hline \multicolumn{2}{|c|}{$75 \% P$} & 77.02 & 80.02 & 50.69 & 52.43 & 1.24 & 1.27 \\
\hline \multicolumn{2}{|c|}{$50 \% \mathrm{p}$} & 68.97 & 73.60 & 43.66 & 45.20 & 1.18 & 1.20 \\
\hline \multicolumn{2}{|c|}{ E. cloacae } & 81.77 & 86.49 & 52.98 & 53.66 & 1.27 & 1.27 \\
\hline \multicolumn{2}{|c|}{$E .+100 \% \mathrm{P}$} & 142.82 & 142.90 & 61.53 & 61.29 & 1.98 & 2.00 \\
\hline \multicolumn{2}{|c|}{$E .+75 \% \mathrm{P}$} & 147.07 & 146.82 & 60.39 & 60.36 & 2.35 & 2.33 \\
\hline \multicolumn{2}{|c|}{$E .+50 \% \mathrm{P}$} & 118.49 & 119.13 & 52.08 & 52.27 & 1.97 & 1.93 \\
\hline \multicolumn{2}{|l|}{ F. Test } & $* *$ & $* *$ & $* *$ & $* *$ & $* *$ & $* *$ \\
\hline \multicolumn{2}{|l|}{ LSD 0.05} & 7.28 & 7.47 & 4.00 & 3.43 & 0.21 & 0.18 \\
\hline
\end{tabular}

N.S $=$ Non significant, $\quad *=$ significant and $* *=$ highly significant 
increase in fresh and dry weight of shoot and rhizome except for dry weight of shoot. The recorded data in Tables (5 and 6) show that plants which received $50 \%$ of the recommended dose of phosphorus fertilizer, inoculated with $E$. cloacae and sprayed with compost tea gave the heaviest fresh weight of shoot (276.2 and $271.6 \mathrm{~g} \mathrm{plant}^{-1}$ ) in both seasons respectively. On the other hand, the heaviest fresh weight of rhizome was 359.9 and $346.3 \mathrm{~g} \mathrm{plant}^{-1}$ in the first and second seasons respectively. Dry weight of rhizome had a similar trend to that observed for fresh weight in both seasons compared with control which gave the lowest values. In this respect, Habib and Zaghloul (2012) studied effect of biofertilizer (Nitrobein and Phosphorene), compost and potassium fertilizer on growth, flowering and chemical constituents of Chrysanthemum frutescence, the study showed that inoculation with phospherene $\left(3 \mathrm{~g} \mathrm{pot}^{-1}\right)+$ compost at $24 \mathrm{~g}$ pot $^{-1}$ gave the highest values of fresh and dry weight of shoots and roots in the first and second seasons. Zantedeschia plants were inoculated with the arbuscular mycorrhizal fungs and fertilized weekly with $50 \mathrm{ml}$ liquid fertilizer containing three different rates of phosphorus (1) no additional (2) $7.5 \mathrm{mg} \mathrm{l}^{-1}$ and (3) $15 \mathrm{mg}^{-1}$. and plants were inoculated with AMF and moderate $\mathrm{P}$ rate $\left(7.5 \mathrm{mg} \mathrm{l}^{-1}\right)$ produced larger tubers than non-inoculated plants. Scagel and Schreiner (2006) concluded that on soybean treated with compost tea was more effective an increasing the root nodule formation by 7.25 times than untreated with compost tea and promoted the growth of root and shoot of both soybean and sweet corn, as these results indicated that aerated compost tea (ACT) could be used as liquid nutrient fertilizer with active microorganisms (Kim et al., 2015).

\section{Flower production:}

\section{Stalk length and diameter $(\mathrm{cm})$ :}

Data presented in Table (6) show that phosphorus fertilizer levels significantly affected stalk length and diameter $(\mathrm{cm})$ in Zantedeschia aethiopiza in respect to $E$. cloacae inoculation it significantly increased stalk length and diameter $(\mathrm{cm})$ compared with un-inoculation treatments. This may be due to that $E$. cloacae increases available phosphorus to plants because it produces acids that increase phosphorus dissolving and produce some hormones which enhance plant shoot, root growth and nutrient uptake.

Highly significant effect for the interaction between phosphorus fertilizer at $50 \%$ of the recommended dose, E. cloacae inoculation and compost tea spraying on stalk length and diameter were 62.73 and $62.28 \mathrm{~cm}$ for stalk length and $2.57 \mathrm{~cm}$ for stalk diameter during the two seasons, respectively. In recent years, interest in the use of PGPR to promote plant growth has increased. Beneficial effects of PGPR on plant growth involves abilities to act as phytostimulators; biofertilizers. PGPR could enhance crop yield through nutrients uptake and plant growth regulators. Their application of Enterobacter as crop inoculants for biofertilization would be an attractive option to reduce the use of chemical fertilizers (Bloemberg and Lugtenberg, 2001; Vessey, 2003).

Data presented in Table (7) showed that Enterobacter inoculation significantly increased inflorescence height and diameter with increasing P-rate and inoculation only. On the other, hand spraying with compost tea increased significantly inflorescence height and diameter, the highest values of inflorescence height and diameter were obtained from Zantedeschia aethiopica plants inoculated with Enterobacter at the rate of $50 \%$ P-fertilizer of the recommended dose sprayed with compost tea. The maximum increase for inflorescence height (cm) was with rate 29.08 and $27.02 \%$ over the control, while increased inflorescence diameter with rate of 31.05 and $44.9 \%$ over the control in the first and second seasons, respectively. E. cloacae inoculation 
Table (7). Effect of chemical, biofertilization and spraying with compost tea on fresh weight of flowering spike ( $\mathrm{g}$ plant ${ }^{-1}$ ) and inflorescence height and diameter (cm) of Zantedeschia aethiopica $\mathbf{L}$.

\begin{tabular}{|c|c|c|c|c|c|c|c|}
\hline \multicolumn{2}{|c|}{ Treatments } & \multicolumn{2}{|c|}{ Inflorescence height (cm) } & \multicolumn{2}{|c|}{$\begin{array}{c}\text { Inflorescence diameter } \\
(\mathrm{cm})\end{array}$} & \multicolumn{2}{|c|}{$\begin{array}{c}\text { Flowering spike fresh } \\
\text { weight (g) }\end{array}$} \\
\hline Main & Sub plot & Season 1 & Season 2 & Season 1 & Season 2 & Season 1 & Season 2 \\
\hline \multirow[t]{8}{*}{ Control } & Control & 8.48 & 8.66 & 7.15 & 7.17 & 16.96 & 16.66 \\
\hline & $100 \% \mathrm{P}$ & 10.70 & 10.67 & 8.13 & 8.50 & 22.80 & 23.78 \\
\hline & $75 \% P$ & 9.79 & 9.92 & 7.60 & 7.97 & 20.31 & 22.88 \\
\hline & $50 \% \mathrm{p}$ & 9.63 & 9.37 & 6.82 & 6.97 & 18.70 & 19.82 \\
\hline & E. cloacae & 9.87 & 10.10 & 7.40 & 7.87 & 24.14 & 25.79 \\
\hline & $E .+100 \% \mathrm{P}$ & 10.00 & 10.93 & 9.10 & 9.37 & 28.40 & 30.70 \\
\hline & $E .+75 \% \mathrm{P}$ & 10.62 & 10.57 & 9.10 & 9.43 & 28.69 & 29.77 \\
\hline & $E .+50 \% \mathrm{P}$ & 9.93 & 9.99 & 8.83 & 8.60 & 27.57 & 26.34 \\
\hline \multirow[t]{8}{*}{ Compost tea } & Control & 9.53 & 9.20 & 7.64 & 7.50 & 20.34 & 19.99 \\
\hline & $100 \% P$ & 9.87 & 9.70 & 8.18 & 8.62 & 27.84 & 29.44 \\
\hline & $75 \% P$ & 9.88 & 9.60 & 8.11 & 7.67 & 25.01 & 28.05 \\
\hline & $50 \% p$ & 9.87 & 9.40 & 8.03 & 7.70 & 22.95 & 23.96 \\
\hline & E. cloacae & 9.97 & 9.83 & 8.21 & 8.40 & 28.76 & 30.85 \\
\hline & $E .+100 \% \mathrm{P}$ & 10.60 & 9.93 & 9.30 & 9.26 & 29.15 & 29.57 \\
\hline & $E .+75 \% \mathrm{P}$ & 10.53 & 10.33 & 9.13 & 9.25 & 29.25 & 30.93 \\
\hline & $E .+50 \% \mathrm{P}$ & 10.94 & 11.00 & 9.37 & 10.39 & 29.82 & 31.74 \\
\hline F. Test & & $* *$ & $* *$ & $* *$ & $* *$ & $*$ & $*$ \\
\hline L.S.D 0.05 & & 1.4 & 1.33 & 1.24 & 0.9 & 3.9 & 3.76 \\
\hline \multicolumn{8}{|c|}{ Main plot } \\
\hline \multicolumn{2}{|c|}{ Control } & 10.00 & 9.88 & 8.02 & 8.23 & 23.45 & 24.47 \\
\hline \multicolumn{2}{|c|}{ Compost tea } & 10.03 & 10.03 & 8.50 & 8.60 & 26.64 & 28.07 \\
\hline \multirow{2}{*}{\multicolumn{2}{|c|}{$\begin{array}{l}\text { F. Test } \\
\text { LSD 0.05 }\end{array}$}} & N.S & N.S & $* *$ & $*$ & $* *$ & $* *$ \\
\hline & & -- & -- & 0.44 & 0.32 & 1.38 & 1.33 \\
\hline \multicolumn{8}{|c|}{ Sub plot } \\
\hline \multicolumn{2}{|c|}{ Control } & 9.01 & 8.93 & 7.40 & 7.33 & 18.65 & 18.32 \\
\hline \multicolumn{2}{|c|}{$100 \% \mathrm{P}$} & 10.28 & 10.18 & 8.16 & 8.56 & 25.32 & 26.61 \\
\hline \multicolumn{2}{|c|}{$75 \% P$} & 9.83 & 9.76 & 7.86 & 7.82 & 22.66 & 25.46 \\
\hline \multicolumn{2}{|c|}{$50 \% p$} & 9.75 & 9.39 & 7.43 & 7.33 & 20.82 & 21.89 \\
\hline \multicolumn{2}{|c|}{ E. cloacae } & 9.92 & 9.97 & 7.81 & 8.13 & 26.45 & 28.32 \\
\hline \multicolumn{2}{|c|}{$E .+100 \% \mathrm{P}$} & 10.77 & 10.97 & 9.23 & 9.88 & 29.11 & 31.22 \\
\hline \multicolumn{2}{|c|}{$E .+75 \% \mathrm{P}$} & 10.58 & 10.45 & 9.12 & 9.34 & 28.97 & 30.35 \\
\hline \multicolumn{2}{|c|}{$E .+50 \% \mathrm{P}$} & 9.97 & 9.96 & 9.07 & 8.93 & 28.36 & 27.95 \\
\hline \multicolumn{2}{|l|}{ F. Test } & $* *$ & $* *$ & $* *$ & $* *$ & $* *$ & $* *$ \\
\hline \multicolumn{2}{|l|}{ LSD 0.05} & 0.99 & 0.94 & 0.44 & 0.64 & 2.77 & 2.66 \\
\hline
\end{tabular}

$\mathbf{N . S}=$ Non significant, $\quad *=$ significant and $* *=$ highly significant 
significantly increased fresh weight of flowering spike as compared with uninoculation under 50 and $75 \%$ phosphorus fertilizer of the recommended dose, spraying with compost tea give the heaviest fresh weight of flowering spike compared to control, the highest values of flowering fresh weight were observed with $E$. cloacae inoculation, 50\% phosphorus fertilizer and spraying with compost tea as gave 29.82 and $31.74 \mathrm{~g} \mathrm{plant}{ }^{-1}$ in the two seasons respectively. However, Suprapta et al. (2014). Studied the potential use of Enterobacter cloacae isolated from rhizospheres of Imperata cylindrica to promote the growth and increase the yield of rice under greenhouse experiments. Treatments with isolates of E. cloacae significantly improved the growth of rice seedlings, plant height, root length, number of roots, number of tillers, content of macro nutrients in the leaf and the dry weight of shoot and root, when compared to control.

Data presented in Table (8) showed that E. cloacae inoculation induced highly significant effect on total inflorescence clump $^{-1}$ and vase life (days) with decreased P-rate. Spraying with compost tea significantly increased number of inflorescences and vase life. The highest number of inflorescences and vase life were obtained with E. cloacae inoculation, 50\% phosphorus fertilizer and spraying with compost tea (9.67 and 9.33) for number of inflorescence and longest vase life were 9.33 during two seasons respectively on the contrary control treatments recorded the lowest values. Spraying Zantedeschia with compost tea highly significant increased flowering spike dry weight $(\mathrm{g})$ as shown in Table (8), E. cloacae inoculation significantly increased flowering spike dry weight $\left(\mathrm{g}\right.$ plant $\left.{ }^{-1}\right)$ in Zantedeschia, the heaviest dry weight of flowering spike were 8.75 and $9.51 \mathrm{~g}$ obtained with E. cloacae inoculation and fertilized with $75 \%$ phosphorus fertilizer of the recommended dose during the two seasons, respectively compared with non-inoculation as shown in Figure (3). These results are in agreement with those of Verma and Shahi ( 2015) and Rana et al. (2011) on potato and wheat respectively.

\section{Macronutrients in shoot (\% of DW):}

Results presented in Table (9) illustrated that chemical and biofertilization treatments raised nitrogen, phosphorus and potassium concentration in shoots compared with control plants in both seasons. In this context, spraying plants with compost tea increased $\mathrm{N}, \mathrm{P}$ and $\mathrm{K} \%$ in shoots. The interaction between chemical, biofertilizer and spraying with compost tea gave the highest $\mathrm{N}, \mathrm{P}$ and $\mathrm{K} \%$ in leaves, the highest $\mathrm{N}$ values (2.90 and $3.29 \%$ ) were obtained with $50 \%$ phosphorus fertilizer of the recommended dose, E. cloacae inoculation and spraying with compost tea. At the same trend increased $\mathrm{P}$ and $\mathrm{K} \%$ in shoots as the highest $\mathrm{P}$ values were $(0.43 \%)$ in each seasons, in respect to $\mathrm{K} \%$ which was $(2.0 \%)$ during two seasons, respectively. These results are in agreement with Pant et al. (2012) who found that applications of compost tea increased growth and mineral nutrient content of Brassica rapa.

Table (10) shows that highly significant effect of bio and chemical fertilizer on flowering date during the first and the second seasons. On the other hand, the combination between spraying with compost tea and E. cloacae inoculation under $50 \%$ of phosphorous recommended dose promoted early flower emergence, where the flowering started 125 days after shoot emergence in both seasons. Data presented in Table (10) illustrated that the effect of inoculation with E. cloacae on flowering period was highly significant under all levels of phosphorous fertilization. Interaction effect between the phosphorus fertilizer levels, E. cloacae inoculation and compost tea spraying showed highly significant effect on flowering period, the plants fertilized with $50 \%$ phosphorus fertilizer of the 
Table (8). Effect of chemical, biofertilization and spraying with compost tea on dry weight of flowering spike (g plant ${ }^{-1}$ ), total inflorescence and vase life (days) of Zantedeschia aethiopica L. in two seasons.

\begin{tabular}{|c|c|c|c|c|c|c|c|}
\hline \multicolumn{2}{|c|}{ Treatments } & \multicolumn{2}{|c|}{$\begin{array}{c}\text { Flowering spike dry } \\
\text { weight (g) }\end{array}$} & \multicolumn{2}{|c|}{$\begin{array}{l}\text { No. of inflorescence/ } \\
\text { clump }\end{array}$} & \multicolumn{2}{|c|}{ Vase life (days) } \\
\hline Main & Sub plot & Season 1 & Season 2 & Season 1 & Season 2 & Season 1 & Season 2 \\
\hline \multirow[t]{8}{*}{ Control } & Control & 2.51 & 2.02 & 3.33 & 4.33 & 5.00 & 4.00 \\
\hline & $100 \% \mathrm{P}$ & 3.31 & 3.60 & 5.00 & 4.67 & 6.00 & 6.33 \\
\hline & $75 \% \mathrm{P}$ & 6.33 & 3.32 & $4.00 \mathrm{f}$ & 3.33 & 6.00 & 6.00 \\
\hline & $50 \% p$ & 3.24 & 6.05 & 3.00 & 3.33 & 5.67 & 5.67 \\
\hline & E. cloacae & 5.19 & 7.48 & 4.33 & 5.00 & 7.67 & 7.33 \\
\hline & $E .+100 \% P$ & 6.09 & 3.33 & 6.00 & 6.00 & 7.67 & 9.00 \\
\hline & $E .+75 \% \mathrm{P}$ & 6.90 & 5.05 & 5.33 & 5.67 & 8.00 & 8.67 \\
\hline & $E .+50 \% \mathrm{P}$ & 6.41 & 7.06 & 4.00 & 5.00 & 8.33 & 8.33 \\
\hline \multirow[t]{8}{*}{ Compost tea } & Control & 5.86 & 7.80 & 5.33 & 6.33 & 5.33 & 5.33 \\
\hline & $100 \% P$ & 8.91 & 8.64 & 8.67 & 9.33 & 6.33 & 6.00 \\
\hline & $75 \% P$ & 6.69 & 7.41 & 8.00 & 9.00 & 6.67 & 7.33 \\
\hline & $50 \%$ p & 6.27 & 10.25 & 6.67 & 7.33 & 7.00 & 7.67 \\
\hline & E. cloacae & 8.29 & 11.42 & 8.67 & 9.00 & 8.00 & 8.33 \\
\hline & $E .+100 \% \mathrm{P}$ & 10.73 & 7.41 & 9.00 & 9.33 & 9.00 & 9.33 \\
\hline & E. $+75 \% \mathrm{P}$ & 10.59 & 7.96 & 9.67 & 9.33 & 9.33 & 9.33 \\
\hline & $E .+50 \% \mathrm{P}$ & 8.57 & 9.27 & 8.67 & 8.67 & 9.00 & 9.00 \\
\hline F. Test & & N.S & N.S & $*$ & $*$ & $*$ & $*$ \\
\hline L.S.D 0.05 & & -- & -- & 1.66 & 1.70 & 1.07 & 1.15 \\
\hline \multicolumn{8}{|c|}{ Main plot } \\
\hline \multicolumn{2}{|c|}{ Control } & 4.86 & 5.15 & 4.38 & 4.67 & 6.79 & 6.92 \\
\hline \multicolumn{2}{|c|}{ Compost tea } & 8.00 & 8.36 & 8.08 & 8.54 & 7.58 & 7.79 \\
\hline F. Test & & $* *$ & $* *$ & $* *$ & $* *$ & $* *$ & $* *$ \\
\hline LSD 0.05 & & 0.76 & 0.80 & 0.59 & 0.6 & 0.38 & 0.41 \\
\hline \multicolumn{8}{|c|}{ Sub plot } \\
\hline \multicolumn{2}{|c|}{ Control } & 4.19 & 4.91 & 4.33 & 5.33 & 5.17 & 4.67 \\
\hline \multicolumn{2}{|c|}{$100 \% \mathrm{P}$} & 6.11 & 6.12 & 6.83 & 7.00 & 6.17 & 6.17 \\
\hline \multicolumn{2}{|c|}{$75 \% \mathrm{P}$} & 5.01 & 5.36 & 6.00 & 6.17 & 6.33 & 6.67 \\
\hline \multicolumn{2}{|c|}{$50 \%$ p } & 4.76 & 4.65 & 4.83 & 5.33 & 6.33 & 6.67 \\
\hline \multicolumn{2}{|c|}{ E. cloacae } & 6.74 & 6.45 & 6.50 & 7.00 & 7.83 & 7.83 \\
\hline \multicolumn{2}{|c|}{$E .+100 \% P$} & 8.41 & 8.87 & 7.50 & 7.67 & 8.33 & 9.17 \\
\hline \multicolumn{2}{|c|}{$E .+75 \% \mathrm{P}$} & 8.75 & 9.51 & 7.50 & 7.50 & 8.67 & 9.00 \\
\hline \multicolumn{2}{|c|}{$E .+50 \% \mathrm{P}$} & 7.49 & 8.16 & 6.33 & 6.83 & 8.67 & 8.67 \\
\hline \multicolumn{2}{|l|}{ F. Test } & $* *$ & $* *$ & $*$ & $*$ & $* *$ & $* *$ \\
\hline \multicolumn{2}{|l|}{ LSD 0.05} & 1.53 & 1.61 & 1.18 & 1.2 & 0.76 & 0.81 \\
\hline
\end{tabular}

N.S $=$ Non significant, $*=$ significant and $* *=$ highly significant 
Table (9). Effect of chemical, biofertilization and spraying with compost tea on $N, P$ and $\mathrm{K} \%$ in shoot after harvest of Zantedeschia aethiopica $\mathrm{L}$. in two seasons.

\begin{tabular}{|c|c|c|c|c|c|c|c|}
\hline \multicolumn{2}{|c|}{ Treatments } & \multicolumn{2}{|c|}{$\mathbf{N \%}$} & \multicolumn{2}{|c|}{$\mathbf{P \%}$} & \multicolumn{2}{|c|}{ K\% } \\
\hline Main & Sub plot & Season 1 & Season 2 & Season 1 & Season 2 & Season 1 & Season 2 \\
\hline \multirow[t]{8}{*}{ Control } & Control & 1.56 & 1.81 & 0.15 & 0.14 & 1.31 & 1.32 \\
\hline & $100 \% P$ & 2.13 & 2.11 & 0.23 & 0.21 & 1.49 & 1.50 \\
\hline & $75 \% \mathrm{P}$ & 2.19 & 2.07 & 0.18 & 0.20 & 1.45 & 1.45 \\
\hline & $50 \%$ p & 2.10 & 2.02 & 0.18 & 0.18 & 1.44 & 1.43 \\
\hline & E. cloacae & 2.07 & 2.01 & 0.18 & 0.19 & 1.40 & 1.42 \\
\hline & $E .+100 \% \mathrm{P}$ & 2.62 & 2.43 & 0.26 & 0.24 & 1.53 & 1.51 \\
\hline & $E .+75 \% \mathrm{P}$ & 2.63 & 2.57 & 0.27 & 0.27 & 1.52 & 1.50 \\
\hline & $E .+50 \% \mathrm{P}$ & 1.84 & 2.00 & 0.25 & 0.24 & 1.48 & 1.48 \\
\hline \multirow[t]{8}{*}{ Compost tea } & Control & 1.59 & 1.69 & 0.19 & 0.19 & 1.46 & 1.44 \\
\hline & $100 \% \mathrm{P}$ & 2.26 & 2.56 & 0.28 & 0.26 & 1.54 & 1.55 \\
\hline & $75 \% \mathrm{P}$ & 2.56 & 2.41 & 0.27 & 0.27 & 1.44 & 1.51 \\
\hline & $50 \%$ p & 2.48 & 2.36 & 0.27 & 0.25 & 1.49 & 1.50 \\
\hline & E. cloacae & 2.61 & 2.56 & 0.27 & 0.27 & 1.57 & 1.56 \\
\hline & $E .+100 \% P$ & 2.86 & 2.84 & 0.40 & 0.40 & 1.71 & 1.72 \\
\hline & E. $+75 \% \mathrm{P}$ & 2.90 & 2.82 & 0.39 & 0.41 & 1.70 & 1.90 \\
\hline & $E .+50 \% \mathrm{P}$ & 2.90 & 3.29 & 0.43 & 0.43 & 2.00 & 2.00 \\
\hline F. Test & & $* *$ & $* *$ & $* *$ & $* *$ & $* *$ & $* *$ \\
\hline L.S.D 0.05 & & 0.43 & 0.40 & 0.03 & 0.03 & 0.12 & 0.11 \\
\hline \multicolumn{8}{|c|}{ Main plot } \\
\hline \multicolumn{2}{|c|}{ Control } & 2.14 & 2.13 & 0.21 & 0.21 & 1.45 & 1.45 \\
\hline \multicolumn{2}{|c|}{ Compost tea } & 2.52 & 2.57 & 0.31 & 0.31 & 1.61 & 1.65 \\
\hline \multirow{2}{*}{\multicolumn{2}{|c|}{$\begin{array}{l}\text { F. Test } \\
\text { LSD } 0.05\end{array}$}} & $* *$ & $* *$ & $* *$ & $* *$ & $* *$ & $* *$ \\
\hline & & 0.15 & 0.14 & 0.01 & 0.01 & 0.04 & 0.04 \\
\hline \multicolumn{8}{|c|}{ Sub plot } \\
\hline \multicolumn{2}{|c|}{ Control } & 1.58 & 1.75 & 0.17 & 0.17 & 1.39 & 1.38 \\
\hline \multicolumn{2}{|c|}{$100 \% \mathrm{P}$} & 2.19 & 2.34 & 0.25 & 0.24 & 1.51 & 1.53 \\
\hline \multicolumn{2}{|c|}{$75 \% \mathrm{P}$} & 2.38 & 2.24 & 0.23 & 0.23 & 1.45 & 1.48 \\
\hline \multicolumn{2}{|c|}{$50 \%$ p } & 2.29 & 2.19 & 0.23 & 0.21 & 1.47 & 1.46 \\
\hline \multicolumn{2}{|c|}{ E. cloacae } & 2.34 & 2.28 & 0.22 & 0.23 & 1.49 & 1.49 \\
\hline \multicolumn{2}{|c|}{$E .+100 \% P$} & 2.75 & 2.63 & 0.33 & 0.32 & 1.62 & 1.62 \\
\hline \multicolumn{2}{|c|}{ E. $+75 \% \mathrm{P}$} & 2.76 & 2.69 & 0.33 & 0.34 & 1.61 & 1.70 \\
\hline \multicolumn{2}{|c|}{$E .+50 \% P$} & 2.37 & 2.65 & 0.34 & 0.34 & 1.74 & 1.74 \\
\hline F. Test & & $* *$ & $* *$ & $* *$ & $* *$ & $* *$ & $* *$ \\
\hline LSD 0.05 & & 0.30 & 0.29 & 0.02 & 0.02 & 0.08 & 0.08 \\
\hline
\end{tabular}

N.S= Non significant, $*=$ significant and $* *=$ highly significant 
Table (10). Effect of chemical, biofertilization and spraying with compost tea on flowering date and period (days) and Dehydrogenase activity in soil of Zantedeschia aethiopica $\mathrm{L}$. in two seasons.

\begin{tabular}{|c|c|c|c|c|c|c|c|}
\hline \multicolumn{2}{|c|}{ Treatments } & \multicolumn{2}{|c|}{$\begin{array}{c}\text { Flowering date } \\
\text { (days) }\end{array}$} & \multicolumn{2}{|c|}{$\begin{array}{c}\text { Flowering period } \\
\text { (days) }\end{array}$} & \multicolumn{2}{|c|}{ 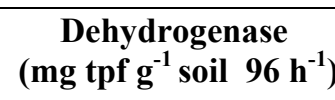 } \\
\hline Main & Sub plot & Season 1 & Season 2 & Season 1 & Season 2 & Season 1 & Season 2 \\
\hline \multirow[t]{8}{*}{ Control } & Control & 163.67 & 162.33 & 223.00 & 227.00 & 60.64 & 65.38 \\
\hline & $100 \% \mathrm{P}$ & 142.33 & 139.33 & 233.00 & 230.67 & 74.06 & 76.14 \\
\hline & $75 \% P$ & 140.67 & 138.67 & 237.00 & 240.33 & 67.63 & 68.59 \\
\hline & $50 \% \mathrm{p}$ & 149.00 & 150.00 & 243.00 & 245.67 & 58.71 & 64.58 \\
\hline & E. cloacae & 158.00 & 152.00 & 244.67 & 243.67 & 73.41 & 75.98 \\
\hline & $E .+100 \% \mathrm{P}$ & 142.33 & 139.67 & 249.00 & 250.33 & 80.32 & 84.42 \\
\hline & $E .+75 \% \mathrm{P}$ & 135.67 & 133.33 & 252.00 & 250.33 & 87.07 & 86.83 \\
\hline & $E .+50 \% \mathrm{P}$ & 157.67 & 156.33 & 252.67 & 252.00 & 75.58 & 75.66 \\
\hline \multirow[t]{8}{*}{ Compost tea } & Control & 155.00 & 156.33 & 259.67 & 258.67 & 73.17 & 72.21 \\
\hline & $100 \% \mathrm{P}$ & 140.00 & 140.67 & 270.00 & 271.00 & 73.09 & 78.47 \\
\hline & $75 \% P$ & 134.33 & 140.33 & 272.67 & 272.33 & 79.36 & 80.08 \\
\hline & $50 \% p$ & 138.33 & 138.33 & 274.67 & 274.00 & 74.38 & 76.22 \\
\hline & E. cloacae & 135.67 & 135.00 & 276.33 & 277.00 & 77.75 & 77.51 \\
\hline & $E .+100 \% P$ & 131.00 & 135.00 & 280.00 & 281.00 & 106.99 & 112.05 \\
\hline & $E .+75 \% \mathrm{P}$ & 126.00 & 127.00 & 282.33 & 282.00 & 121.69 & 125.94 \\
\hline & $E .+50 \% \mathrm{P}$ & 125.00 & 125.33 & 285.67 & 285.67 & 146.35 & 143.86 \\
\hline F. Test & & $* *$ & $* *$ & N.S & $* *$ & $* *$ & $* *$ \\
\hline L.S.D 0.05 & & 9.5 & 6.7 & -- & 3.69 & 5.94 & 5.94 \\
\hline \multicolumn{8}{|c|}{ Main plot } \\
\hline \multicolumn{2}{|c|}{ Control } & 148.67 & 146.46 & 241.79 & 242.50 & 72.18 & 74.70 \\
\hline \multicolumn{2}{|c|}{ Compost tea } & 135.67 & 137.25 & 275.17 & 275.21 & 94.10 & 95.79 \\
\hline \multirow{2}{*}{\multicolumn{2}{|c|}{$\begin{array}{l}\text { F. Test } \\
\text { LSD } 0.05\end{array}$}} & $* *$ & $* *$ & $* *$ & $* *$ & $* *$ & $* *$ \\
\hline & & 3.36 & 2.37 & 1.97 & 1.31 & 2.099 & 2.10 \\
\hline \multicolumn{8}{|c|}{ Sub plot } \\
\hline \multicolumn{2}{|c|}{ Control } & 159.33 & 159.33 & 241.33 & 242.83 & 66.91 & 68.80 \\
\hline \multicolumn{2}{|c|}{$100 \% \mathrm{P}$} & 141.17 & 140.00 & 251.50 & 250.83 & 73.57 & 77.31 \\
\hline \multicolumn{2}{|c|}{$75 \% P$} & 135.00 & 136.83 & 254.83 & 256.33 & 73.49 & 74.34 \\
\hline \multicolumn{2}{|c|}{$50 \% p$} & 143.67 & 144.17 & 258.83 & 259.83 & 66.55 & 70.40 \\
\hline \multicolumn{2}{|c|}{ E. cloacae } & 146.83 & 143.50 & 260.50 & 260.33 & 75.58 & 76.75 \\
\hline \multicolumn{2}{|c|}{$E .+100 \% \mathrm{P}$} & 136.67 & 137.33 & 264.50 & 265.67 & 93.65 & 98.23 \\
\hline \multicolumn{2}{|c|}{$E .+75 \% \mathrm{P}$} & 133.33 & 132.00 & 267.17 & 266.17 & 104.38 & 106.39 \\
\hline \multicolumn{2}{|c|}{$E .+50 \% \mathrm{P}$} & 141.33 & 141.67 & 269.17 & 268.83 & 110.96 & 109.76 \\
\hline \multicolumn{2}{|l|}{ F. Test } & $* *$ & $* *$ & $* *$ & $* *$ & $* *$ & $* *$ \\
\hline \multicolumn{2}{|l|}{ LSD 0.05} & 6.72 & 4.74 & 3.94 & 2.61 & 4.199 & 4.22 \\
\hline
\end{tabular}

N.S $=$ Non significant, $*=$ significant and $* *=$ highly significant 


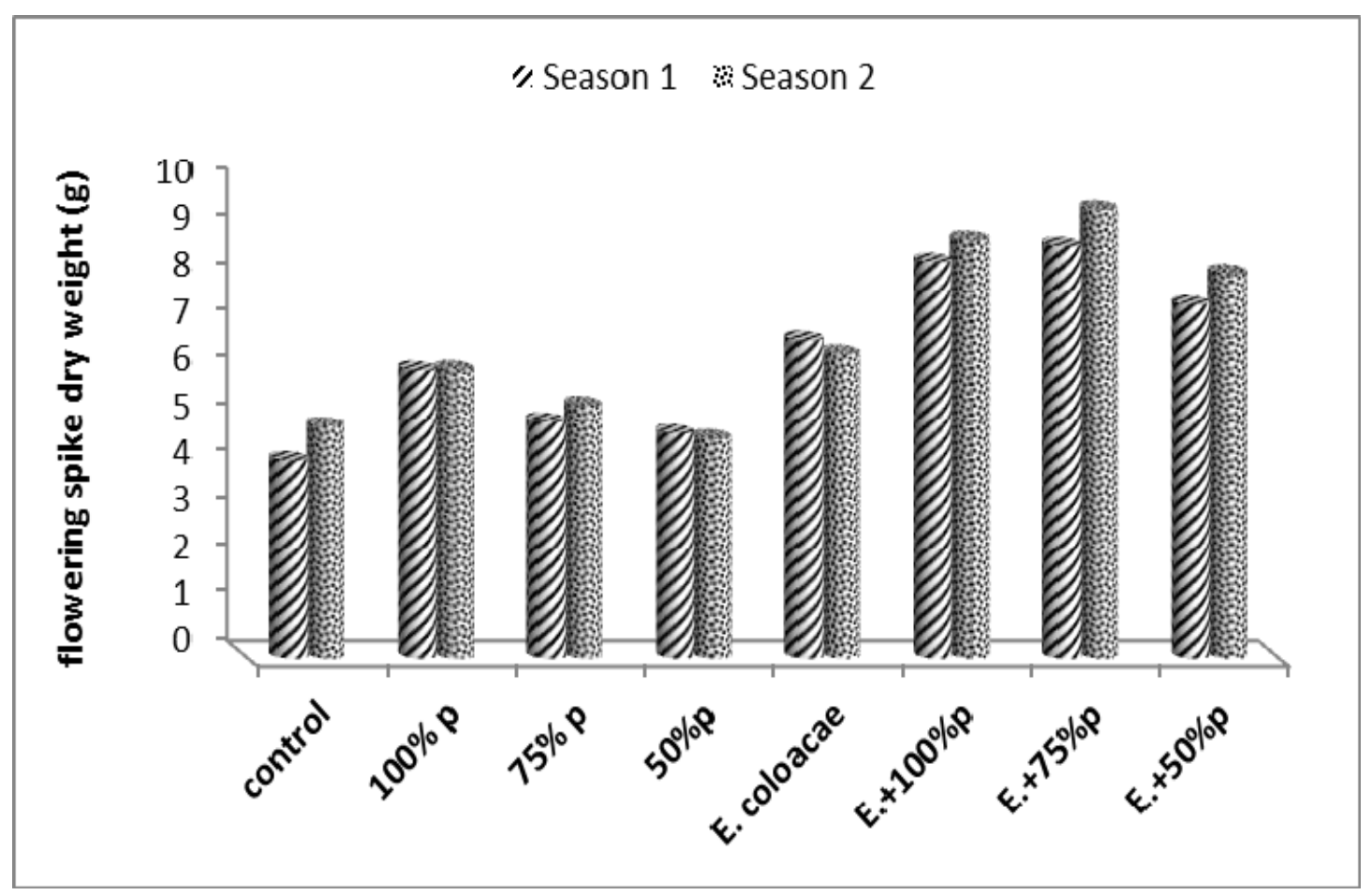

Figure (3). Flowering spike dry weight of Zantedeschia aethiopica L. in two seasons as affected by $E$. cloacae under phosphorus fertilization levels of.

recommended dose, inoculated with $E$. cloacae and sprayed with compost tea increased the duration of flower production of plant to $285.7 \mathrm{~d}$. during the second season.

The strain (Enterobacter) was found to give high yield of IAA $(0.89 \mathrm{mg} / \mathrm{ml})$ from watermelon seed powder and it was also found to produce other plant growth promoting substances such as siderophore, ammonia, organic acids and hydrogen cyanide so enhanced the productivity and quality of crops (Attar et al., 2015).

\section{Dehydrogenase activity:}

Concerning dehydrogenase activity in soils results showed that there was a highly significant response to E. cloacae inoculation, P-fertilization levels and the interaction between both factors, the highest activity of dehydrogenase in soil was obtained by plant inoculation with $E$. cloacae, soil application 50\% phosphorus fertilizer of the recommended dose and spraying with compost tea as were (146.35

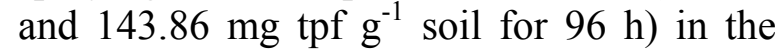
two seasons respectively over the control.
The use of biofertilizers for harvesting effect on the naturally available, biological system of nutrient mobilization in soil (Venkatashwarlu, 2008). E. cloacae can produce phosphate solubilization, siderophore, and indole acetic acid synthesis and using as bio-inoculant to increase the productivity of crops and reduce chemical fertilizers (Ahemad and Khan, 2010).

inoculation with $E$. cloacae significantly increased activity of dehydrogenase under phosphorus fertilization levels., where the activity of dehydrogenase recorded 110.97 and $109.76 \mathrm{mg}$ tpf $\mathrm{g}^{-1}$ soil $96 \mathrm{~h}^{-1}$ obtained with E. cloacae inoculation and fertilized with $50 \%$ phosphorus fertilizer of the recommended dose during the two seasons respectively compared with non-inoculated treatments as shown in Figure (4). Generally, spraying with compost tea increased the activity of dehydrogenase in soil, under all experimental treatments the maximum increase were 28.25 and $30.35 \%$ compared with control during the two seasons as shown in Figure (5). 


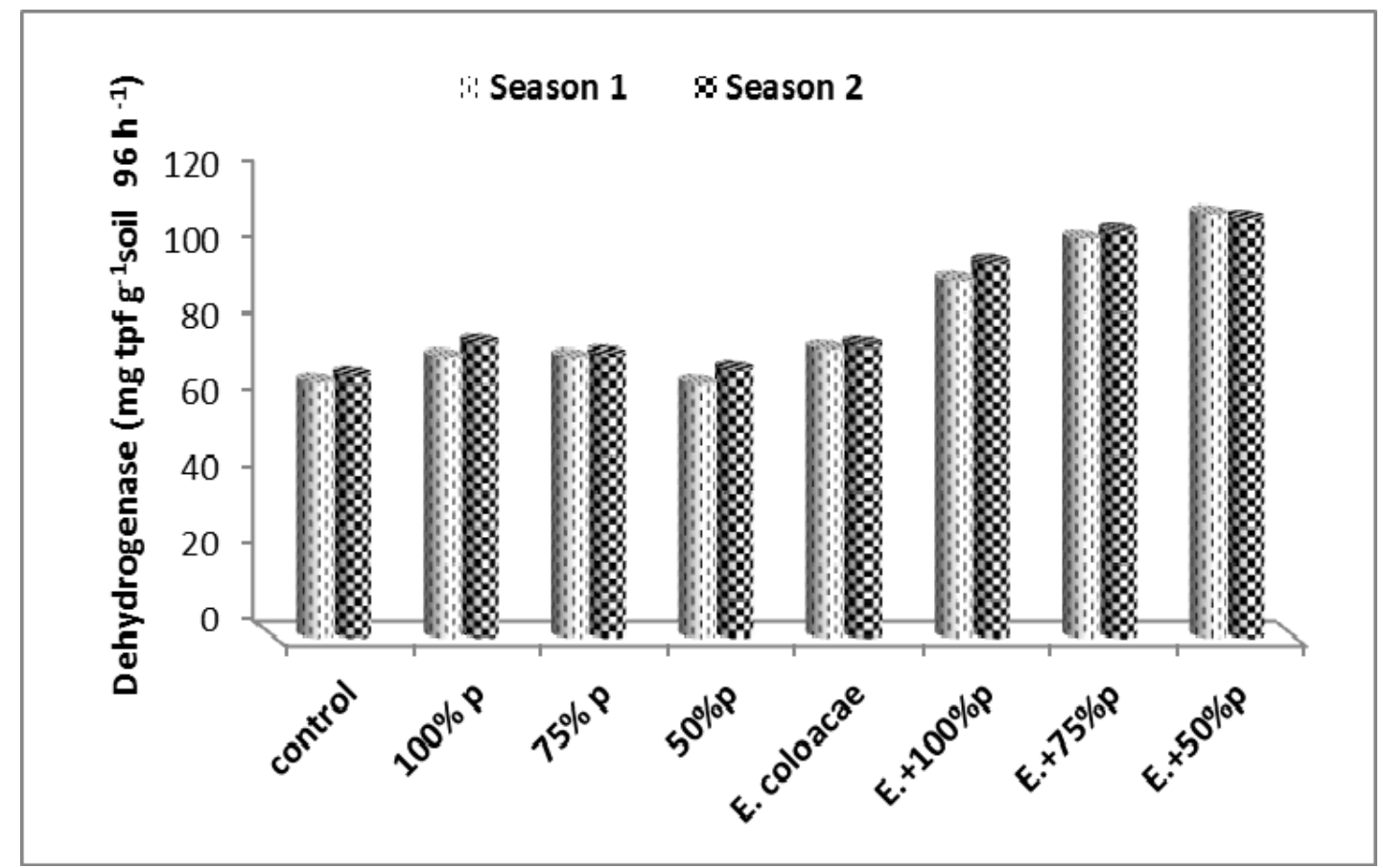

Figure (4). Dehydrogenase activity (mg tpf $\mathrm{g}^{-1}$ soil $\left.96 \mathrm{~h}^{-1}\right)$ in soil affected by $E$. cloacae under phosphorus fertilization levels.

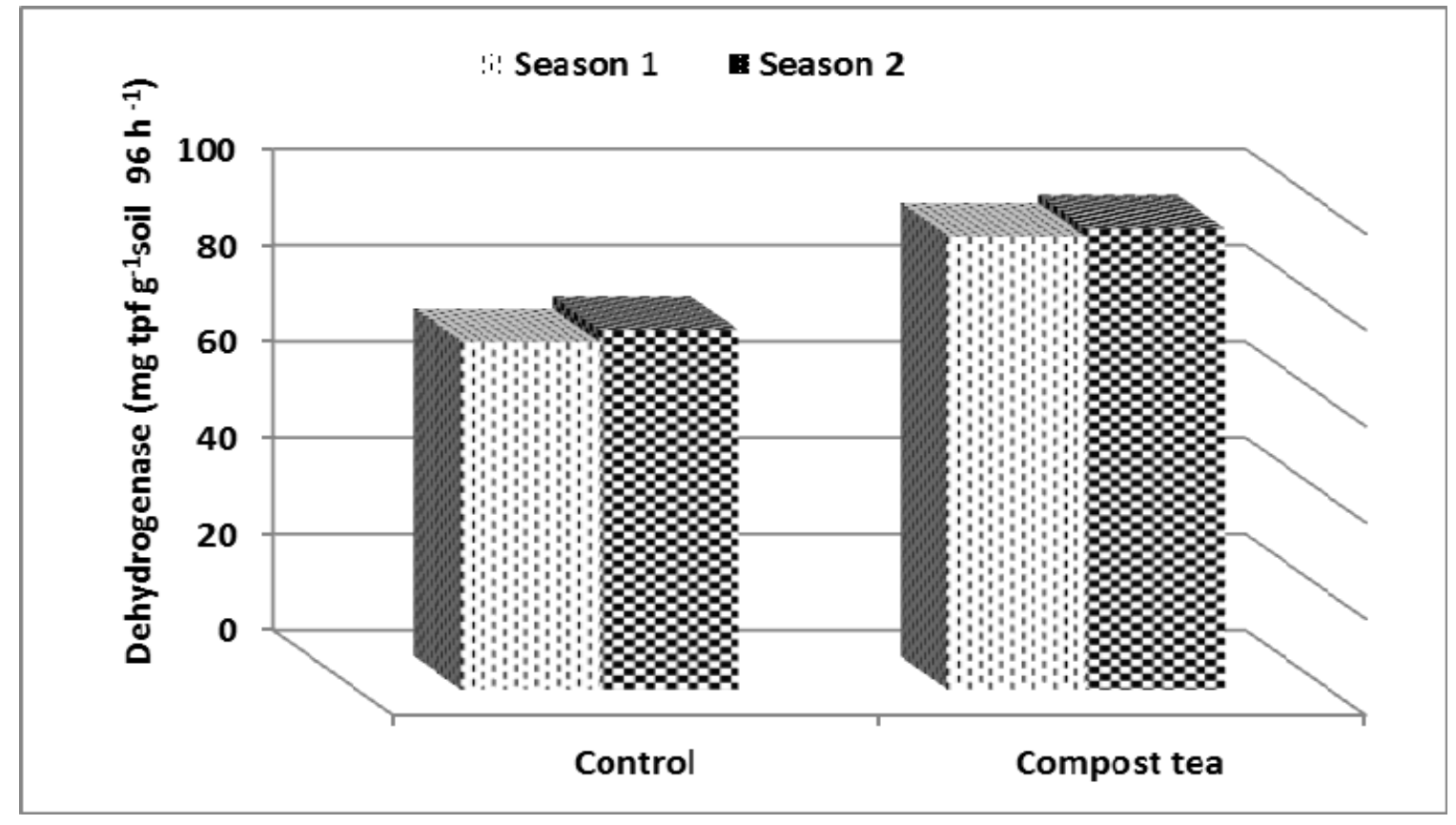

Figure (5). Dehydrogenase activity (mg tpf $\mathrm{g}^{-1}$ soil $96 \mathrm{~h}^{-1}$ ) in soil affected by compost tea spraying. 


\section{REFERENCES}

A.O.A.C. (1984). Official Methods of Analysis, $12^{\text {th }}$ Ed. Association Official Analytical Chemists, Washington, D.C., U.S.A.

Abo El-Nour, E.A.; El-Sayed, A.A. and ElBendary, A.A. (1996). Effect of phosphate biofertilizer (phosphrein) on growth, yield and nutrient uptake of Faba bean plants. J. Agric. Sci. Mansoura Univ., 21:477-483.

Ahemad, M. and Khan, M.S. (2010). Plant growth promoting activities of phosphate solubilizing Enterobacter asburiae as influenced by fungicides. EurAsian Journal of Bio Sciences, 4:88-95.

Attar, Y.C.; Mali, S.D. and Kamble, P.P. (2015). Study of phosphate solubilizing Enterobacter cloacae sub sp. cloacae strain YCA for production of plant growth promoting substances. International Journal of Pure and Applied Bioscience, 3 (1):71-80.

Attia, E.A.A.M. (2004). Physiological Studies on Some Ornamental Bulbs, Ph.D. Thesis, Derpartment of Horticulture, Kafr El-Sheik, Tanta University.

Bhattacharyya, P.N. and Jha, D.K. (2012). Plant growth-promoting rhizobacteria (PGPR): emergence in agriculture. World J Microbiol Biotechnol, 28:1327-1350.

Black, A.C.; Evans, D.D.; White, J.L.; Ensminyer, E.L. and Clark, E.F. (1965). Methods of Soil Analysis Amer. Soc. Agro. Inc. Madison Wisconsin, USA.

Bloemberg, G.V. and Lugtenberg, B.J.J. (2001). Molecular basis of plant growth promotion and biocontrol by rhizobacteria. Curr Opin Plant Biol., 4:43-350.

Brown, J.D. and Lilliland, O.C. (1946). Rapid determination of potaasium and sodium in plant material and soil extracts by flame photometer Proc. Amer. Soc. Hort., Sci., 48:341-346.

Diver, S. (2007). Notes on Compost Teas: A Supplement to the ATTRA Publication: Compost Teas for Plant Disease Control. Appropriate Technology Transfer for Rural Areas (ATTRA). Available: http://www.attra.ncat.org.

Funnell, K.A. (1993). Zantedeschia. Physiology of Flowering Bulbs, Elsevier, Amsterdam, The Netherlands. In: A. De Hertogh and M. Le Nard (eds.), p. 683704.

Gupta, G.; Parihar, S.S.; Ahirwar; N.K., Snehi, S.K., and Singh, V. (2015). Plant growth promoting rhizobacteria (PGPR): current and future prospects for development of sustainable agriculture. Journal of Microbial and Biochemical Technology.

Habib, A.M. and Zaghloul, S.M. (2012). Effect of chemical, organic and biofertilization on growth and flowering of Chrysanthemum frutescens, plants. Journal of Horticultural Science and Ornamental Plants, 4 (2):186-194.

Hargreaves, C.J.; Adla, M. and Warmanb, P.R. (2009). Are compost tea an effective nutrient amendment in the cultivation of strawberries?. Science of Food and Agriculture, 89 (3):390-397.

Henny, R.J. (1999). Stimulating flowering of ornamental aroid genera with gibberellic acid: A review. Proc. Florida St. Hort. Soc., 108:23-24.

Ingram D.T. and Millner, P.D. (2007). Factors affecting compost tea as a potential source of Escherichia coli and Salmonella on fresh produce. J. Food Prod., 70:828-834.

Jackson, M.L. (1967). Soil Chemical Analysis. Prentice-Hall, India, New Delhi, pp: 183-203.

Khan, M.S.; Zaidi, A.; Ahemad, M.; Oves M. and Wani, P.A. (2010). Plant growth 
promotion by phosphate solubilizing fungi-current perspective. Arch. Agron. Soil Sci., 56:73-98.

Kim, M.J.; Shim, K.M.; Kim, C.; Hong, Y.K., and Park, J.H. (2015). Effect of aerated compost tea on the growth promotion of lettuce, soybean, and sweet corn in organic cultivation, The Plant Pathology Journal, 31(3):259-268.

Kloepper, J.W. and Schroth, M.N. (1981). Relationship of in vitro antibiosis of plant growth promoting rhizobacteria to plant growth and the displacement of root microflora. Phytopathol, 71:1020-1024.

Klute, A. (1986). Methods of Soil Analysis Part 1: Physical and Mineralogical Methods, $2^{\text {nd }}$ ed. Amer. Soc. Agron. Madison Wisconsin, USA.

Naor, V.; Kigel, J. and Ziv, M. (2004). Hormonal control of inflorescence development in plantlets of calla lily (Zantedeschia spp.) grown in vitro. Plant Growth Reg., 42:7-14.

Pant, A.P.; Radovich, T.J.; Hue, N.V. and Paull, R.E. (2012). Biochemical properties of compost tea associated with compost quality and effects on pak choi growth. Scientia horticulturae, 148:138146.

Pant, A.P.; Radovich, T.J.; Hue, N.V.; Talcott, S.T. and Krenek, K.A. (2009). Vermicompost extracts influence growth, mineral nutrients, phytonutrients and antioxidant activity in pak choi (Brassica rapa $\mathrm{cv}$. Bonsai, Chinensis group) grown under vermicompost and chemical fertiliser. Journal of the Science of Food and Agriculture, 89(14):2383-2392.

Rana, A.; Saharan, B.; Joshi, M.; Prasanna, R.; Kumar, K. and Nain, L. (2011). Identification of multi-trait PGPR isolates and evaluating their potential as inoculants for wheat. Ann. Microbiol., 61:893-900

Saharan, B.S. and Nehra, V. (2011). Plant Growth Promoting Rhizobacteria: A
Critical Review. Life Sciences and Medicine Research, 21:1-30.

Scagel, C.F. and Schreiner, R.P. (2006). Phosphorus supply alters tuber composition, flower production, and mycorrhizal responsiveness of containergrown hybrid Zantedeschia, Plant and Soil, 283:323-337.

Sharma, S.B.; Sayyed, R.Z., Trivedi, M.H. and Gobi, T.A. (2013). Phosphate solubilizing microbes: sustainable approach for managing phosphorus deficiency in agricultural soils. Springerplus, 2: 587.

Snedecor, G.W. and Cochran, W.G. (1989). Statistical Methods, Eighth Edition, Iowa State University Press. Ames., Iowa.

Snell, F.D. and Snell, C.T. (1967). Colorimetric Methods of Analysis. D. Van Nostrand Company Inc., pp: 551552.

Steel, R.G.D. and Torrie, F.H. (1980). Principles and Procedures of Statistics. $2^{\text {nd }}$ Ed., Mc Graw Book Co., New York.

Suprapta, D.N.; Maulina, N.M.I. and Khalimi, K. (2014). Effectiveness of Enterobacter cloacae to promote the growth and increase the yield of rice. Journal of Biology, Agriculture and Healthcare, 4(1).

Tabatabai, M.A. (1982). Soil enzymes, Dehydrogenases. In: Methods of Soil Analysis. Part 2: Chemical and Microbiolgical Properties (Eds R.H. Miller and D.R. Keeney). Agron. Monography, 9, ASA and SSSA, Madison.

Venkatashwarlu, B. (2008). Role of biofertilizers in organic farming: Organic farming in rain fed agriculture: Central institute for dry land agriculture, Hyderabad, 85-95.

Verma, P. and Shahi, S.K. (2015). Isolation and characterization of bacterial isolates from potato rhizosphere as potent plant 


\section{Azza A. Ghazi and Eman A. Attia}

growth promoters, International Journal of Current Microbiology and Applied Science, 4(3): 521-528.

Vessey, J.K. (2003). Plant growth promoting rhizobacteria as biofertilizers. Plant Soil, 255:571-586.

Welke, S.E. (2005). The effect of compost extract on the yield of strawberries and the severity of Botrytis cinerea. Journal of Sustainable Agriculture, 25(1):57-68.
Weltzein, H.C. (1991). Biocontrol of foliar fungal disease with compost extracts. In: Andrewsa J.H.; Hirano S. (eds). Microbial Ecology of Leaves, 430-450. Springer- verlag, New York, NY, USA.

Youssef, A.M.; El-Fouly, A.H.M.; Youssef, M.S. and Mohanedien, S.A. (2001). Effect of using organic and chemical fertilizers in firtigation system on yield and fruit quality of tomato. J. Hort., 28:59-77.

\section{تأثير التسميا الكيماوي والحيوي والرش بشاي الكمبوست على نمو وانتاجية ابصال الكلا$$
\text { عزة عبدالسلام غازي * و إيمان علي عطيه }
$$

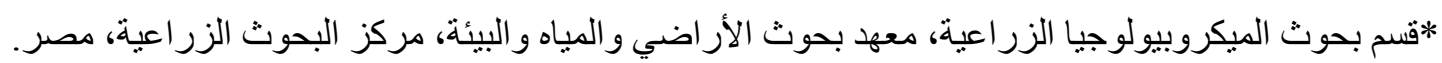

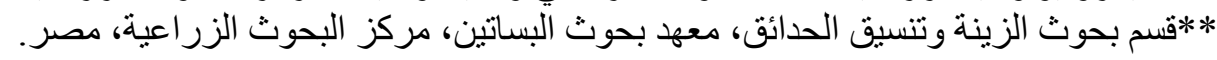

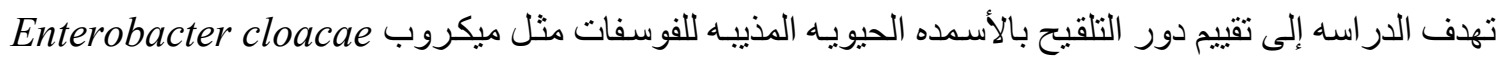

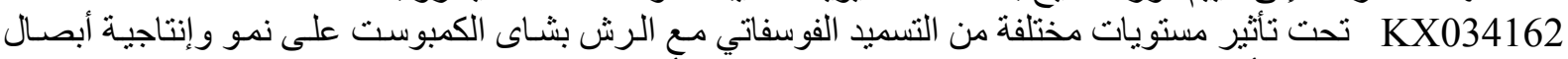

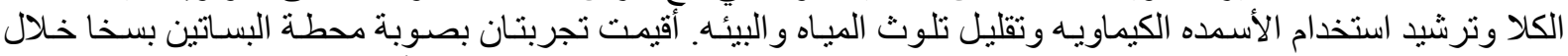

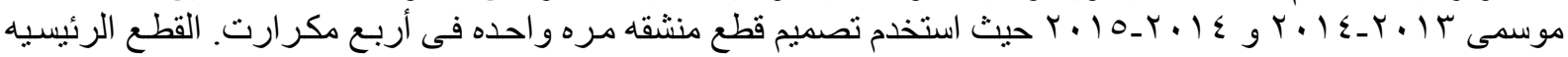

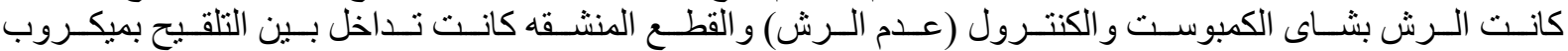

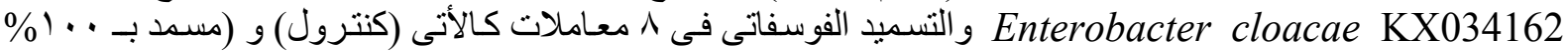

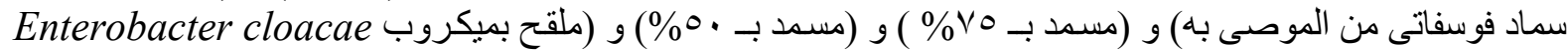

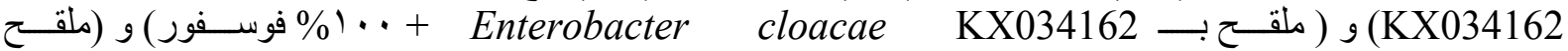

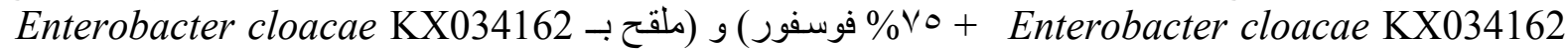

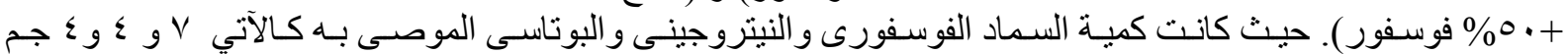

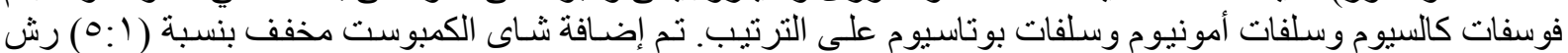

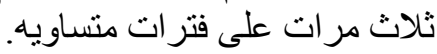
و وتتلخص النتائج فى الأتى:

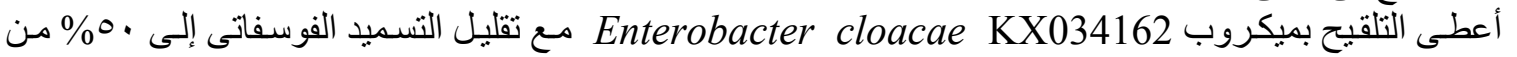

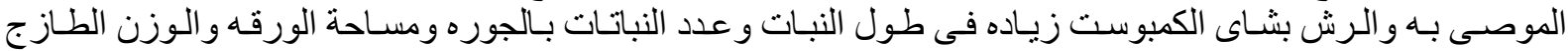

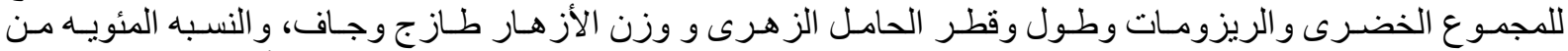

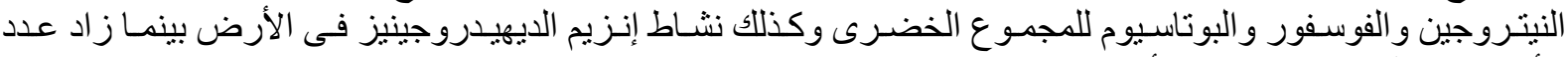
الازز هار فى الجوره ومدة بقاء الأز هار. 